\title{
The Drosophila gene Hairless encodes a novel basic protein that controls alternative cell fates in adult sensory organ development
}

\author{
Anne G. Bang and James W. Posakony \\ Department of Biology and Center for Molecular Genetics, University of California at San Diego, \\ La Jolla, California 92093-0322 USA
}

\begin{abstract}
The mechanosensory bristles of adult Drosophila are composed of four cells that, in most cases, are progeny of a single sensory organ precursor (SOP) cell. Two sister cells in this lineage, the trichogen and tormogen, produce the external shaft and socket of the bristle, respectively. Loss-of-function mutations of Hairless $(H)$ confer two distinct mutant phenotypes on adult bristles. The bristle loss phenotype results from the failure to specify and/or execute the SOP cell fate; the double socket phenotype results from the transformation of the trichogen (shaft) cell into a second tormogen (socket) cell. We have found that the $H$ gene encodes a novel basic protein with a predicted molecular mass of $109 \mathrm{kD}$. Basal levels of expression of a transgene $(\mathrm{P}[\mathrm{Hs}-\mathrm{H}])$ in which the $H$ protein-coding region is under the control of the $H$ sp 70 promoter are sufficient to provide full rescue of $\boldsymbol{H}$ mutant phenotypes. Heat shock treatment of $\mathrm{P}[\mathrm{Hs}-\mathrm{H}]$ transgenic animals as late larvae and early pupae produces a tormogen-to-trichogen (double shaft) cell fate transformation, as well as bristle multiplication and loss phenotypes very similar to those caused by loss-of-function mutations in the neurogenic gene Notch. Our results indicate that the SOP cell fate requires $H$ to antagonize the activity of the neurogenic group of genes and that the expression of distinct cell fates by the trichogen/tormogen sister cell pair depends on an asymmetry in their levels of $\mathrm{H}^{+}$activity or in their thresholds for response to $\boldsymbol{H}$.
\end{abstract}

[Key Words: Drosophila; Hairless; peripheral nervous system; sensory organ development; cell fate; neurogenic genes]

Received April 23, 1992; revised version accepted July 8, 1992.

The peripheral nervous system (PNS) of adult Drosophila is composed of an elaborate array of epidermally derived sensory organs, or sensilla, that are organized in a characteristic pattern on the body surface. Each sensillum is composed of one or more neurons and a number of non-neuronal accessory cells. For example, a typical mechanosensory sensillum (bristle) includes a single bipolar neuron and three different accessory cells / thecogen, trichogen, and tormogen) that form sheaths around the dendrite of the neuron and produce the external stimulus-receiving apparatus. In particular, the shaft of the bristle is the product of the trichogen cell, whereas the socket is made by the tormogen cell.

In most cases, the cells comprising an individual mechanosensory sensillum are generated by a fixed lineage from a single sensory organ precursor (SOP) cell; in this lineage, the neuron and thecogen are sister cells, as are the trichogen and tormogen (Hartenstein and Posakony 1989). The SOPs arise during the late larval and early pupal stages in the imaginal discs and histoblast nests, undifferentiated epithelial sheets that give rise to the cuticular structures of the adult fly. SOP determina- tion appears to occur in two steps. The spatially restricted expression of the achaete and scute genes, which encode transcriptional regulatory proteins of the helixloop-helix class, first establishes a pattern of proneural clusters of cells that are competent to become SOPs $\mid \mathrm{Cu}$ bas et al. 1991; Skeath and Carroll 1991). Local inhibitory cell-cell interactions requiring the activity of the neurogenic genes Notch $(N)$, Delta (Dl), Enhancer of split $[E(s p l)]$, neuralized (neu), and mastermind (mam) then ensure that only a single cell in each proneural cluster, the SOP, will actually give rise to a sensory organ (Dietrich and Campos-Ortega 1984; Hartenstein and Posakony 1990; Simpson 1990).

It appears that similar inhibitory cell-cell interaction mechanisms are involved in the determination of both the SOPs and their postmitotic progeny. Thus, we have shown that $N^{+}$activity is required not only to restrict the expression of the SOP fate within the proneural cluster but also to restrict the expression of the sensory neuron fate among the presumptive sensillum cells (Hartenstein and Posakony 1990).

Recently, it has become clear that another gene, Hair- 
less $(H)$, also plays an essential role in controlling both the SOP fate and the fates of individual sensory organ cells (Bang et al. 1991). Loss-of-function mutations of $H$ confer two distinct mutant phenotypes on the bristle sensilla of adult Drosophila. The bristle loss phenotype, in which bristles fail to appear on the body surface, results from the failure to specify and/or execute the SOP cell fate (Bang et al. 1991). The double socket phenotype represents a later differentiative defect and results from a nearly complete transformation of the trichogen (shaft) cell into a second tormogen (socket) cell (Lees and Waddington 1942; Bang et al. 1991). In the case of strong $H$ alleles, these phenotypic effects are dominant and are the result of haploinsufficiency of $H^{+}$function. $H$ null alleles are recessive lethal in the larval/pupal stage.

$H$ loss-of-function mutations have also been shown to exhibit strong phenotypic interactions with mutant alleles of the neurogenic genes (see Lindsley and Zimm 1992). In general, in both embryos and adults, $H$ suppresses the mutant phenotypes caused by neurogenic loss-of-function alleles (Dietrich and Campos-Ortega 1984; Vässin et al. 1985; de la Concha et al. 1988) and enhances the phenotypes of gain-of-function alleles (Knust et al. 1987). $H$ thus acts genetically as an antagonist of neurogenic gene activity. The observation that in the embryo, $H$ suppresses the neural hyperplasia resulting from homozygosity for loss-of-function alleles of $N, D l$, neu, and mam, but not $E(s p l)$, has led to the suggestion that among the neurogenic genes $E(s p l)$ may be the major target of $H$ function (Vässin et al. 1985; de la Concha et al. 1988).

Here, we report the results of our molecular analysis of the $H$ gene, its transcripts, and its predicted protein product. We investigate the spatial pattern of accumulation of $H$ transcripts in the ovary, in embryos, and in larval and pupal imaginal discs. Finally, we examine the phenotypic consequences of overexpression of a $H$ cDNA under the control of a heat shock promoter in transgenic flies.

\section{Results}

\section{Molecular cloning of the $\mathrm{H}$ gene}

The P-element enhancer trap transposon insertion D179 exhibits a weak $H$ phenotype when homozygous, fails to complement a strong $H$ allele $\left(H^{2}\right)$, and maps by in situ hybridization to cytological location 92E14-15 (data not shown), consistent with the position of the $H$ locus as defined by chromosomal rearrangements (92E12-92F1,2; see Bang et al. 1991; Lindsley and Zimm 1992). We tested whether the D179 P-element insertion is the cause of the associated $H$ phenotype by exposing the D179 chromosome to P-transposase activity (Robertson et al. 1988). Revertants to a wild-type phenotype and mutants exhibiting a stronger $H$ phenotype were obtained at high frequency (data not shown).

Genomic DNA flanking the D179 P-element insertion site was isolated by plasmid rescue and used as a probe to recover $\sim 50 \mathrm{~kb}$ of wild-type genomic DNA from a cosmid library. A panel of mutant $H$ alleles generated by $\gamma$-ray mutagenesis (see Bang et al. 1991) was then screened for DNA rearrangements in a $16-\mathrm{kb}$ region surrounding the D179 insertion site by Southern blot hybridization analysis, comparing the $H$ mutant chromosomes with the parental chromosome. Three $H$ mutants, $H^{18}, H^{20}$, and $H^{22}$, were found to be associated with specific molecular lesions (Fig. 1A and data not shown). The identification of this cluster of four specific molecular defects in the D179, $H^{18}, H^{20}$, and $H^{22}$ mutant alleles provided strong evidence that the cloned DNA contains sequences necessary for wild-type $H$ function.

\section{Identification and structure of the $\mathrm{H}$ transcription unit}

The cellular defects in sensory organ development during late larval and early pupal stages in $H$ mutants (Bang et al. 1991), and the genetic interactions between $H$ and several of the neurogenic genes during embryonic neurogenesis (Vässin et al. 1985; de la Concha et al. 1988), suggested that $H$ should be transcribed at least during these stages. cDNA libraries constructed from poly $(\mathrm{A})^{+}$ RNA of 4- to 8-hr embryos and third-instar imaginal discs (Brown and Kafatos 1988) were screened for clones that hybridized to a region of $8 \mathrm{~kb}$ of wild-type genomic DNA spanning the cluster of $H$ molecular lesions. Fourteen independent cDNA clones were recovered that represented the same transcription unit. The structure of this putative $H$ transcription unit, shown in Figure 1A, was deduced by restriction mapping and sequence analysis of the 14 cDNA clones and by limited sequencing of genomic DNA.

We carried out Northern blot hybridization analysis of staged embryonic and pupal poly $(\mathrm{A})^{+}$RNAs using the longest cDNA clone isolated, $2-10$, as a probe. Two major $H$ transcripts of 4.2 and $5.3 \mathrm{~kb}$ were detected in 0 - to 2- and 2- to 4-hr embryos (Fig. 1D). At 4-6 hr of embryogenesis, a novel transcript of $\sim 6.0 \mathrm{~kb}$ appears in addition to the 4.2 - and $5.3-\mathrm{kb}$ species. These three major transcripts continue to be expressed throughout the rest of embryonic development, during the late third-instar larval and early pupal stages and in adult males and females (Fig. 1D and data not shown). We also detected less abundant transcripts of $4.0-$ and $5.0-\mathrm{kb}$ at all stages (Fig. 1D and data not shown). We tentatively concluded that all of these transcripts are products of the $H$ locus because they are encoded by sequences that are disrupted by DNA rearrangements in the D179, $H^{18}, H^{20}$, and $H^{22}$ mutants. Thus, at least five size classes of stable poly $(\mathrm{A})^{+}$RNA are produced by the $H$ transcription unit.

We determined the complete sequence of cDNA clone 2-10, which, as shown below, probably represents a fulllength copy of the $5.3-\mathrm{kb} H$ mRNA (Fig. 2). This sequence includes a single large open reading frame (ORF) capable of encoding a protein of 1059 amino acids (see below). We also obtained an additional $673 \mathrm{bp}$ of unique 3 '-untranslated sequence from cDNA 2-8. The combined sequence from the two cDNA clones totals $5.9 \mathrm{~kb}$ not including the poly(A) tract (Fig. 2), consistent with the 

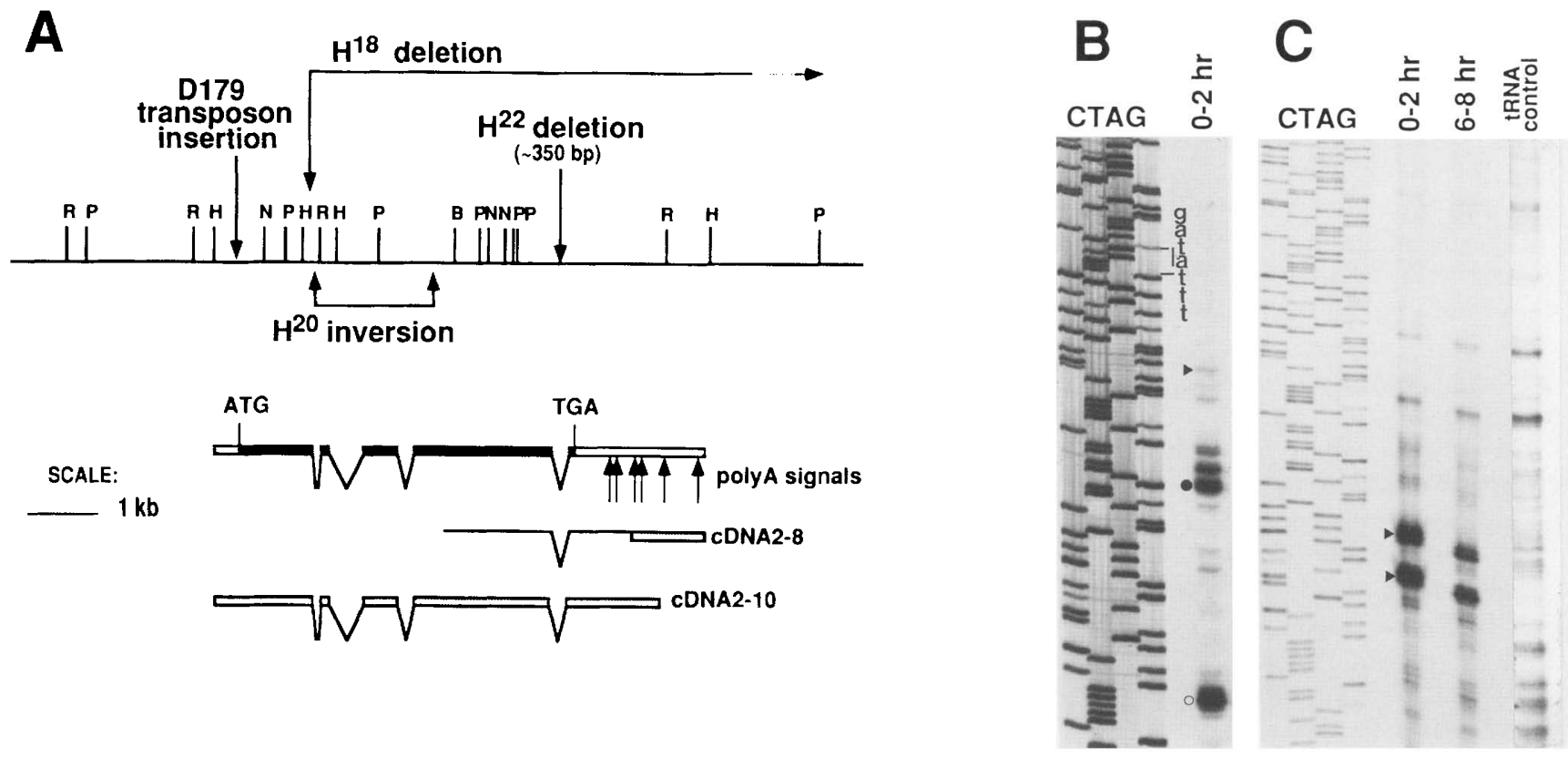

Figure 1. Molecular analysis of the $H$ gene and its transcripts. $(A)$ Genomic organization of the $H$ locus. Restriction map of $\sim 15 \mathrm{~kb}$ of cloned genomic DNA encompassing the $H$ transcription unit, showing sites for BamHI (B), EcoRI $(\mathrm{R}), \operatorname{HindIII}(\mathrm{H})$, $\operatorname{NotI}(\mathrm{N})$, and PstI $(\mathrm{P})$. Positions of the D179 transposon insertion and other allelespecific rearrangements (in $H^{18}, H^{20}$, and $H^{22}$ ) are indicated. The intron/exon structure of the $H$ gene is shown below the genomic DNA map. Exons are indicated by boxes; solid regions represent protein-coding sequence, with start and stop codons marked. The positions of six consensus polyadenylation signals (AATAAA; Wickens 1990$)$ are also indicated. $H$ cDNA clones $2-10$ and 2-8 are aligned beneath; shaded boxes represent sequenced regions. $(B)$ Primer extension analysis. Major $|O|$ and the largest minor (arrowhead) primer extension products of total RNA (150 $\mu \mathrm{g}$ ) from 0- to 2-hr embryos, and a putative TATA box-like sequence (gatattt), are indicated. (O) A primer extension product probably produced by a strong polymerase stop, because no corresponding fragment is detected by RNase protection. A genomic DNA subclone was sequenced with the extension primer to provide a marker (left). Positions of extension products are marked in the $H$ DNA sequence in Fig. 2. Primer extension with total RNA of 6- to 8-hr embryos and total RNA of early pupae yielded similar results (data not shown). (C) RNase protection analysis. Fragments of

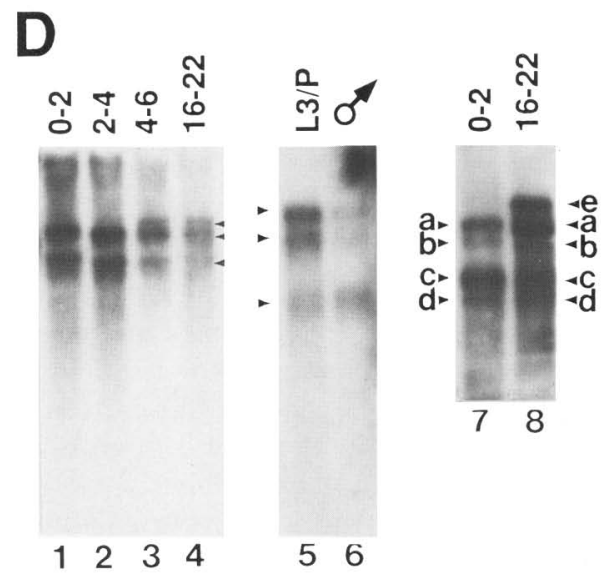
an antisense RNA probe specifically protected from digestion by RNase A and RNase T1 are indicated by arrowheads. Total RNAs (150 $\mu \mathrm{g}$ ) from 0- to 2-hr embryos and poly $(\mathrm{A})^{+}$RNA $(10 \mu \mathrm{g})$ from 6- to 8-hr embryos were analyzed. Nonspecific fragments are identified by their presence in the yeast tRNA $(10 \mu \mathrm{g})$ control lane. A genomic DNA subclone was sequenced and used as a size marker (left; see Materials and methods). (D) Northern blot hybridization analysis of poly(A) ${ }^{+}$RNA $(7 \mu \mathrm{g} /$ lane) from staged embryos (lanes $1-4$ and $7-8$; stages are shown in hours after egg laying), late third-instar larvae/early pupae (lane 5), and adult males (lane 6). Filters were probed with labeled DNA of the cDNA clone $2-10$. In lanes $1-6$, the three major $H$ transcripts of $6.0-, 5.2-$, and $4.2-\mathrm{kb}$ are indicated by arrowheads. The $6.0-\mathrm{kb}$ species is not detected until $4-6 \mathrm{hr}$ of embryogenesis. The three major $H$ transcripts are expressed throughout the rest of embryogenesis (data not shown for 6-16 hr of embryogenesis). RNA samples for lanes 5-8 were electrophoresed for longer than the RNAs shown in lanes $1-4$, to provide greater resolution. In lanes 7 and 8 , at least five transcripts can be distinguished (arrowheads): $a(5.2 \mathrm{~kb}), b(5.0 \mathrm{~kb}), c(4.2 \mathrm{~kb}), d(4.0 \mathrm{~kb}), e(6.0 \mathrm{~kb})$.

size of the longest polyadenylated $H$ transcript that we detected by Northern blot analysis $(6.0 \mathrm{~kb}$; Fig. 1D). Within $2.04 \mathrm{~kb}$ of $3^{\prime}$-untranslated sequence, we identified six consensus polyadenylation signals (AATAAA; Wickens 1990); cDNA clones representing the utilization of the three most distal of these signals were recovered (Figs. 1A and 2; data not shown). We compared the results of Northern blot hybridization experiments that used as a probe either a 402-bp fragment containing the extreme 5 '-terminal untranslated sequence of Figure 2, or a 396-bp fragment containing the extreme 3 '-terminal untranslated sequence. The 5 '-terminal probe hybridized to all $H$ transcripts detected previously by use of cDNA clone $2-10$ as a probe (Fig. ID), whereas the $3^{\prime}$-terminal probe detected only the longest $(6.0 \mathrm{~kb}) \mathrm{H}$ transcript, indicating that the $6.0-\mathrm{kb}$ mRNA results from utilization of the distal-most polyadenylation signal (data not shown).

Primer extension and RNase protection experiments were carried out to map the $H$ transcription start site 
Downloaded from genesdev.cshlp.org on April 26, 2023 - Published by Cold Spring Harbor Laboratory Press

Hairless controls alternative cell fates

$-386$

$-314$

$-242$

$-170$

$-98$

GATATGgGCAGGaCACCAATATCGACGCACGgCAACAACAGCTGgGgCGGCTACGgTGGTCGTTTGCAGTTC $\begin{array}{llllllllllllllllllllllllllllllll}D & M & G & R & T & P & I & S & T & H & G & N & N & S & W & G & G & Y & G & G & R & L & Q & F\end{array}$

\section{$\nabla 1$}

1343 TTTAAAGATGGCAAATTCATATTGGAACTGGCGCGGTCCAAGGATGGCGATAAAAGCGGCTGGGTTTCGGTC $\begin{array}{llllllllllllllllllllllll}F & K & D & G & K & F & I & L & E & L & A & R & S & K & D & G & D & K & S & G & W & V & S & V\end{array}$

1415 ACGCGCAAGACCTTCCGCCCTCCATCGGCGGCCACCTCCGCAACTGTGACCCCAACGTCGGCGGTGACCACA $\begin{array}{llllllllllllllllllllllllllll}T & R & K & T & F & R & P & P & S & A & A & T & S & A & T & V & T & P & T & S & A & V & T & T\end{array}$

Figure 2. (See p. 1758 for legend.)
Asp 718 $M T O$ 


\section{$\mathbf{\nabla 2}$}

1487 GCGTATCCAAAGAACGAGAATTCCACATCGCTGAGCTTTTCGGACGACAACAGCTCGATACAATCCTCTCCT $\begin{array}{llllllllllllllllllllllllll}\text { A } & Y & P & K & N & E & N & S & T & S & L & S & F & S & D & D & N & S & S & I & Q & S & S & P & 291\end{array}$

1559 TGGCAGCGAGACCAGCCCTGGAAACAGTCCCGACCCAGGCGCGGCATATCTAAGGAGCTGTCGCTCTTCTTC $\begin{array}{llllllllllllllllllllllllll}W & Q & R & D & Q & P & W & K & Q & S & R & P & R & R & G & I & S & K & E & L & S & L & F & F & & 315\end{array}$

1631 CACCGCCCCAGGAACAGTACGCTTGGCCGAGCTGCTCTCCGGACAGCCGCTCGCAAACGACGGCGCCCCCAC $\begin{array}{lllllllllllllllllllllllllll}\mathrm{H} & \mathrm{R} & \mathrm{P} & \mathrm{R} & \mathrm{N} & \mathrm{S} & \mathrm{T} & \mathrm{L} & \mathrm{G} & \mathrm{R} & \mathrm{A} & \mathrm{A} & \mathrm{L} & \mathrm{R} & \mathrm{T} & \mathrm{A} & \mathrm{A} & \mathrm{R} & \mathrm{K} & \mathrm{R} & \mathrm{R} & \mathrm{R} & \mathrm{P} & \mathrm{H} & 339\end{array}$

1703 GAGCCGCTTACCACCAGCGAGGATCAGCAGCCCATTTTTGCGACGGCAATCAAGGCGGAAAATGGAGACGAT $\begin{array}{lllllllllllllllllllllllll}E & P & L & T & T & S & E & D & Q & Q & P & I & F & A & T & A & I & K & A & E & N & G & D & D & 363\end{array}$

1775 ACTCTTAAAGCAGAAGCTGCAGAGGCCGTTGAAATTGAAAATGTTGCTGTGGCGGACACAACCACAAATGAG $\begin{array}{lllllllllllllllllllllllll}T & \mathrm{~L} & \mathrm{~K} & \mathrm{~A} & \mathrm{E} & \mathrm{A} & \mathrm{A} & \mathrm{E} & \mathrm{A} & \mathrm{V} & \mathrm{E} & \mathrm{I} & \mathrm{E} & \mathrm{N} & \mathrm{V} & \mathrm{A} & \mathrm{V} & \mathrm{A} & \mathrm{D} & \mathrm{T} & \mathrm{T} & \mathrm{T} & \mathrm{N} & \mathrm{E} & 387\end{array}$

1847 ATTAAAATTGAAAAACCGGACACGATCAAAGGCGAGGATGATGCTGAACGGCTCGAAAAGGAGCCGAAGAAG $\begin{array}{lllllllllllllllllllllllll}I & K & I & E & K & P & D & T & I & K & G & E & D & D & A & E & R & L & E & K & E & P & K & K & 411\end{array}$

1919 GCGGTTAGCGATGATAGCGAGTCAAAAGAAGCATCGCCCGGTCAGCAAGTGGAACCACAACCAAAAGATGAG $\begin{array}{lllllllllllllllllllllllll}A & V & S & D & D & S & E & S & K & E & A & S & P & G & Q & Q & V & E & P & Q & P & K & D & E & 435\end{array}$

1991 ACTGTTGATGTTGAGATGAAGATGAATACGAGCGAGGATGAGGAACCCATGACAGAGCTGCCCAGAATCACG $\begin{array}{lllllllllllllllllllllllll}T & V & D & V & E & M & K & M & N & T & S & E & D & E & E & P & M & T & E & L & P & R & I & T & 459\end{array}$

2063 AATGCCGTAAATGGTGATCTAAACGGCGATCTAAAGGCGAGCATTGGGAAACCAAAATCCAAGCCGAAGCCA $\begin{array}{lllllllllllllllllllllllllll} & N & A & V & N & G & D & L & N & G & D & L & K & A & S & I & G & K & P & K & S & K & P & K & P & 483\end{array}$

2135 AAAGCCAAGCTCAGCAGCATCATTCAGAAACTCATCGATAGCGTACCAGCACGGCTTGAGCAAATGTCGAAG $\begin{array}{lllllllllllllllllllllllll}K & A & K & \text { L } & S & S & I & I & Q & K & \text { L } & \text { I } & \text { D } & S & \text { V } & \text { P } & A & \text { R } & \text { L } & \text { E } & \text { Q } & \text { M } & \text { S } & \text { K } & 507\end{array}$

2207 ACATCAGCTGTGATCGCATCGACAACGACGTCTTCAGATCGCATTGGTGGCGGTCTAAGTCACGCCTTGACG $\begin{array}{lllllllllllllllllllllllll}T & S & A & V & I & A & S & T & T & T & S & S & D & R & I & G & G & G & L & S & H & A & L & T & 531\end{array}$

$\nabla 3$

2279 CACAAAGTTTCTCCACCCTCTTCTGCGACAGCAGCCGGACGACTAGTCGAGTACCACACCCAGCACGTGTCG $\begin{array}{lllllllllllllllllllllllll}\mathrm{H} & \mathrm{K} & \mathrm{V} & \mathrm{S} & \mathrm{P} & \mathrm{P} & \mathrm{S} & \mathrm{S} & \mathrm{A} & \mathrm{T} & \mathrm{A} & \mathrm{A} & \mathrm{G} & \mathrm{R} & \mathrm{L} & \mathrm{V} & \mathrm{E} & \mathrm{Y} & \mathrm{H} & \mathrm{T} & \mathrm{Q} & \mathrm{H} & \mathrm{V} & \mathrm{S} & 555\end{array}$

2351 CCCAGGAAAAGAATCCTGCGCGAGTTCGAAAAGGTGTCGCTAGAGGACAACGGATGCGTAAACAACGGCAGC $\begin{array}{llllllllllllllllllllllllll}P & R & K & R & I & L & R & E & F & E & K & V & S & L & E & D & N & G & C & V & N & N & G & S & 579\end{array}$

2423 GGTGGAGCTAGTAGCGGTGGTGCTGGAGGAAAACGGAGTCGAGCAAAGGGAACTTCGACATCGTCTCCGGCT $\begin{array}{llllllllllllllllllllllllllllll}G & G & A & S & S & G & G & A & G & G & K & R & S & R & A & K & G & T & S & T & S & S & P & A & 603\end{array}$

2495 GGCAAGGCGTCACCAATGAACTIGGCGCCACCCCAAGGAAAGCCAAGCCCCAGTCCCGGCTCCAGCTCATCC $\begin{array}{llllllllllllllllllllllllll}G & K & A & S & P & M & N & \text { L } & A & P & P & Q & G & K & P & S & P & S & P & G & S & S & S & S & 627\end{array}$

2567 AGCACTTCGCCAGCGACCTTGTCAACGCAGCCAACGCGGCTCAACAGCTCTTACAGTATCCACTCCCTGCTA $\begin{array}{llllllllllllllllllllllllll}S & T & S & P & A & T & L & S & T & Q & P & T & R & L & N & S & S & Y & S & I & H & S & L & L & 651\end{array}$

2639 GGTGGGAGCAGTGGCAGCGGTAGCTCATCCTCCTCCTCCTCTGGCAAGAAGTGCGGCGATCACCCGGCAGCT $\begin{array}{lllllllllllllllllllllllllll}G & G & S & S & G & S & G & S & S & S & S & S & S & S & G & K & K & C & G & D & H & P & A & A & 675\end{array}$

2711 ATTATCAGCAATGTGCACCATCCACAGCACTCAATGTACCAACCCAGTTCCTCGAGCTATCCACGCGCCCTG $\begin{array}{lllllllllllllllllllllllll}I & I & S & N & V & H & H & P & O & H & S & M & Y & Q & P & S & S & S & S & Y & P & R & A & L & 699\end{array}$

2783 CTCACCTCGCCAAAGTCGCCCGATGTGAGTGGCAGCAATGGCGGGGGCGGAAAATCGCCCTCGCATACAGGA $\begin{array}{llllllllllllllllllllllllll}\mathrm{L} & \mathrm{T} & \mathrm{S} & \mathrm{P} & \mathrm{K} & \mathrm{S} & \mathrm{P} & \mathrm{D} & \mathrm{V} & \mathrm{S} & \mathrm{G} & \mathrm{S} & \mathrm{N} & \mathrm{G} & \mathrm{G} & \mathrm{G} & \mathrm{G} & \mathrm{K} & \mathrm{S} & \mathrm{P} & \mathrm{S} & \mathrm{H} & \mathrm{T} & \mathrm{G} & & 723\end{array}$

2855 ACCAAGAAGCGTTCGCCACCGTACTCGGCGGGATCACCCGTAGACTATGGCCACTCCTTCTACAGGGATCCC $\begin{array}{lllllllllllllllllllllllll}T & K & K & R & S & P & P & Y & S & A & G & S & P & V & D & Y & G & H & S & F & Y & R & D & P & 747\end{array}$

2927 TATGCGGGAGCAGGTCGTCCTTCCACATCGGGCTCAGCATCGCAGGACCTGTCGCCACCGCGCTCTTCCCCA $\begin{array}{lllllllllllllllllllllllllll}Y & A & G & A & G & R & P & S & T & S & G & S & A & S & Q & D & L & S & P & P & R & S & S & P & 771\end{array}$

2999 GCATCGCCAGCCACGACGCCGCGTACTGTGCCCAAAAAGACTGCATCGATCCGACGCGAGTTCGCTTCACCG $\begin{array}{lllllllllllllllllllllllll}A & S & P & A & T & T & P & R & T & V & P & K & K & T & A & S & I & R & R & E & F & A & S & P & 795\end{array}$

Figure 2. (See p. 1758 for legend.) 
Downloaded from genesdev.cshlp.org on April 26, 2023 - Published by Cold Spring Harbor Laboratory Press

Hairless controls alternative cell fates

3071 TCGGCCAGCAGCAGTAGCTGTCCCTCGCCCGGCGACCGGAGTGCATCGCCCCCGGAACGGCGGCACATGCAG

$\begin{array}{llllllllllllllllllllllllll}S & A & S & S & S & S & C & P & S & P & G & D & R & S & A & S & P & P & E & R & R & H & M & Q & 819\end{array}$

3143 CAGCAGCCGCACCTACAGCGTAGCTCGCCGCTGCACTACTATATGTACCCGCCACCGCCCCAGGTGAACGGG $\begin{array}{llllllllllllllllllllllllll}Q & Q & P & H & L & Q & R & S & S & P & L & H & Y & Y & M & Y & P & P & P & P & Q & V & N & G\end{array}$

3215 AACGGCTCGGCCGGAAGTCCGACCTCGGCGCCGCCCACGTCGAACAGCAGTGCAGCTGCAGTAGCGGCGGCA $\begin{array}{lllllllllllllllllllllllll}N & G & S & A & G & S & P & T & S & A & P & P & T & S & N & S & S & A & A & A & V & A & A & A & 867\end{array}$

3287 GCAGCGGCCGCAGCCGCATACATTCCCTCGCCTTCGATATACAACCCGTACATATCCACACTGGCGGCGTTG $\begin{array}{lllllllllllllllllllllllllllllll}\text { A } & A & A & A & A & A & Y & I & P & S & P & S & I & Y & N & P & Y & I & S & T & L & A & A & L\end{array}$

3359 AGGCACAATCCGCTGTGGATGCACCACTATCAGACAGGAGCGTCGCCCCTGCTGTCGCCACATCCACAACCC $\begin{array}{lllllllllllllllllllllllll}\text { R } & H & \text { N } & \text { P } & \text { L } & \text { W } & \text { M } & \text { H } & \text { H } & \text { Y } & \text { Q } & \text { T } & \text { G } & \text { A } & \text { S } & \text { P } & \text { L } & \text { L } & \text { S } & \text { P } & \text { H } & \text { P } & \text { Q } & \text { P } & 915\end{array}$

3431 GGTGGCTCAGCGGCCGCCGCTGCTGCAGCTGCTGCTGCGAGATTATCGCCCCAATCGGCCTATCACGCGTTC $\begin{array}{llllllllllllllllllllllllll}G & G & S & A & A & A & A & A & A & A & A & A & A & R & \text { L } & S & \text { P } & \text { Q } & \text { S } & \text { A } & \text { Y } & \text { H } & \text { A } & \text { F } & 939\end{array}$

3503 GCGTATAACGGAGTGGGAGCGGCTGTTGCCGCTGCAGCAGCTGCGGCAGCCTTTGGACAACCGGCGCCCAGT \begin{tabular}{lllllllllllllllllllllllll}
$A$ & $Y$ & $N$ & $G$ & $V$ & $G$ & $A$ & $A$ & $V$ & $A$ & $A$ & $A$ & $A$ & $A$ & $A$ & $A$ & $A$ & $F$ & $G$ & $Q$ & $P$ & A & P & $S$ \\
\hline
\end{tabular}

3575 CCCCACACGCATCCGCACTTGGCCCATCCGCACCAGCATCCGCACCCGGCTGCACTGACCACCCACCACTCT \begin{tabular}{llllllllllllllllllllllllll}
$\mathrm{P}$ & $\mathrm{H}$ & $\mathrm{T}$ & $\mathrm{H}$ & $\mathrm{P}$ & $\mathrm{H}$ & $\mathrm{L}$ & $\mathrm{A}$ & $\mathrm{H}$ & $\mathrm{P}$ & $\mathrm{H}$ & $\mathrm{Q}$ & $\mathrm{H}$ & $\mathrm{P}$ & $\mathrm{H}$ & $\mathrm{P}$ & $\mathrm{A}$ & $\mathrm{A}$ & $\mathrm{L}$ & $\mathrm{T}$ & $\mathrm{T}$ & $\mathrm{H}$ & $\mathrm{H}$ & $\mathrm{S}$ \\
\hline \hline
\end{tabular}

3647 CCCGCTCACCTGGCCACGCCAAAACTGACTGATAGTAGTACCGACCAAATGTCTGCAACGTCCAGTCATCGC $\begin{array}{lllllllllllllllllllllllll}\mathrm{P} & \mathrm{A} & \mathrm{H} & \mathrm{L} & \mathrm{A} & \mathrm{T} & \mathrm{P} & \mathrm{K} & \mathrm{L} & \mathrm{T} & \mathrm{D} & \mathrm{S} & \mathrm{S} & \mathrm{T} & \mathrm{D} & \mathrm{Q} & \mathrm{M} & \mathrm{S} & \mathrm{A} & \mathrm{T} & \mathrm{S} & \mathrm{S} & \mathrm{H} & \mathrm{R} & 1011\end{array}$

3719 ACAGCCTCCACTTCGCCGAGCAGCTCGAGCGCATCGGCCTCCTCCTCGGCGGCCACTTCGGGCGCCAGCTCC $\begin{array}{lllllllllllllllllllllllll}\mathrm{T} & \mathrm{A} & \mathrm{S} & \mathrm{T} & \mathrm{S} & \mathrm{P} & \mathrm{S} & \mathrm{S} & \mathrm{S} & \mathrm{S} & \mathrm{A} & \mathrm{S} & \mathrm{A} & \mathrm{S} & \mathrm{S} & \mathrm{S} & \mathrm{A} & \mathrm{A} & \mathrm{T} & \mathrm{S} & \mathrm{G} & \mathrm{A} & \mathrm{S} & \mathrm{S} & 1035\end{array}$

3791 TCCGCAATGTTTCATACTAGTAGTCTAAGGAATGAACAAAGTTCAGACTTACCACTGAATCTGTCAAAGCAC $\begin{array}{lllllllllllllllllllllllll}\text { S } & A & M & F & H & T & S & S & L & R & N & E & Q & S & S & D & L & P & L & N & \text { L } & S & K & H & 1059\end{array}$ $\star$

TAGCGCTTAAGACGACATTCAATACACGTAATATAATTTGATAAGTTCGCTGATAGTTTAGTTGTAACCCGA TTGTTTAATCCTAAGCCTAATCCTAGGTTCTCAATTAGGGCCGAACATTTAGAAATCGCATACAAAAAGAGA TGAAAAACTCAACTTTGTTTTTAAACCCGTTCCAGAACTCTTTATACAATCAGT TGAGAAAT TT TATTTTCG ACAAACTGAATAAAATATGCAAAGGAATTTTATTCTATGCCGACTAATGGAAAGAAATACT MATAAAACAT TTTCTATAGGATGTATAAAATGCAAGTCTTAAAGAATCTCAAAAAAGAGTTACGTTTTTTTCATCAAAACAT TTCCTTGAAACAGACTGAACCTGAATTTTTTTAGAAAAAAAAAATGAAAAACTTAGTTACGAATCGCAAAAT ATAACATTTTAAAGATATTTAACAAAACTACAAGAACAGATT TT TATAAAATGCTTGTGCCTTTAAAAATGG

\section{ECORV}

AAACAGGCAGGTATTCTATGGTGAAAACTTTAGAATTTCTTGATATCGTGGTCCAAAATGCAGTTGACAGGA ATTTGCACTAAGCAGATTGTATACGACACCAACTTTTTAAGTACTTTTAAAAATGTATCTTTTAATTATTTC GGAATAATTATTCTAAAATAGTTAAAAGA TAAAAGAAATCCAAAACTATACAACTCGTCTGTACTTCAAAAC GAAAGAGATTACTCTTTGGTCTTACATTT TTTGGTAGACTGTAAAAACTAAAAT TCGAAAAAATTGTTGAAG TTTGAATTTAAATCCTCGGCGGATCTAAATTTAACCTCCACGATTGTTGTCACCATCAAAAATATTATATAA CTGTGCCTAGTGCACATTCGCTGTCAGTGGCTGTCCAATCAAAAACAMATAAAATGTACAAAAAATCCACAT ATACGACAAAT TTACAACAAAGGGAAAGCAAAAAGATCCTAAGCAGACAATTTCAAACCGGAACTCGTACAA CTGAAACTGATACAAATAAAAAACATATTCCTAACGCAAAAAGACAAAAACAAAACGCGGTTTCTCATATTT TCTAAATTATTTATATAAATCAAATGTCTATTTATATTTACTGATATGATAATGTGTAAGTAAATAGGTGTA ATTGTAAATACAGTATTTTTACACAACAAAAAGTTAATCAATACGCGAGAAATAACCAAATATATTTAATAT AACTATTTTTATAACGGATTTTAACAAGTAACTGTATATTTTGTATCTGATTACGCAGMATAAAAAACAAAA CGAATTCCATATGAGGTCAAGAACAGTTTGCACAAGGCGGCCTGAAACTTGCTTAAAACTTAATGCACTGAA CAAAATCCGAACTAAACACATCTGTTCCAGGCAGATACAAAATATTTTCCAATGGAAAAATGGAGTAGATTC ATTTATTTTTTACTAATCAATACATAAATCTTTCAGTTCGAAATTTTTAAGCAAGTTGCAGTCGGCTAAACT TTTTAGTAGGCTTTAATGAAAATTAAAAAGAAATATAAATACAATTTTCATACAAATTCCATATGGTTTCTA CTACCTACTGATTAGTTAGTTAGATAGGCGTCTAGGGACTATTAATTTACATTTGTAACGGTACTGTGTACG ACGTTTTTGTTTAACTGAACGGTAGTGTTTTTAATTTGAAATTCGATGTTTTTAGTGAGTGGCTATTGTTGA ACGAACACATGTACTATGTGCATTGTCGAACAATGTGCGCAAACCCAAAAAAATAATTTTGGCAAAAAGTGA AATATATGAAGTAAGCAAATGGTTTCAAGATACTGCATCTCGTGATGTTGGAGTGTGTGTGTAAAGCAAAGG AAACAAAATTAATTTTAAAGAAATATATTTTATATAGGTATATATACTGCAACTGAATACTTGATGTCMATA AAAACTTATACTAAATGTATGAAAACG

Figure 2. (See following page for legend.) 
(Fig. 1B,C). A 5'-end-labeled oligonucleotide complementary to nucleotides $126-151$ of the cDNA $2-10$ sequence (Fig. 2) was annealed to total embryonic RNA and extended with reverse transcriptase. A major extension product (indicated by the solid circle in Fig. 1B) was 151 nucleotides long, coincident with the $5^{\prime}$ end of cDNA 2-10. Five longer, minor extension products were detected within the next 20 nucleotides. A TATA boxlike sequence element GATATTT, which deviates from the consensus TATAA $^{\mathrm{A}} / \mathrm{TA}^{\mathrm{A}}$ (Corden et al. 1980), is located in genomic DNA 27 nucleotides upstream of the end of the longest primer extension product (Fig. 2). Because the primer extension reactions were carried out on RNA treated with the strong denaturant methylmercuric hydroxide, it is unlikely that the multiple extension products resulted from RNA secondary structure that the reverse transcriptase could not resolve. RNase protection experiments confirmed the existence of major transcription starts at or near the positions indicated by primer extension (Fig. 1C). Our results indicate that cDNA clone 2-10, the $5^{\prime}$ end of which coincides with the terminus of a major primer extension product, represents a full-length copy of a $H$ transcript, presumably the 5.3-kb mRNA. The use of the transcription start sites indicated by these $5^{\prime}$ end analyses in conjunction with the polyadenylation signals that we identified (see Figs. $1 \mathrm{~A}$ and 2 ; data not shown) would produce $H$ transcripts similar in size to those we detected on Northern blots (Fig. 1D). We propose that differential polyadenylation gives rise to the array of $H$ transcripts and that these transcripts differ in their lengths of 3 '-untranslated sequence.

The $H$ transcription unit encompasses $\sim 7.5 \mathrm{~kb}$ of genomic DNA (Fig. 1A). Four introns were detected by comparing restriction maps of genomic and cDNA clones (Figs. 1A and 2). The sequences of introns 1 (70 bp) and $4(180 \mathrm{bp})$ were determined in their entirety, whereas only the donor intron/exon junctions for intron $2 / \sim 600$ bp) and intron $3(\sim 200 \mathrm{bp})$ were sequenced. Other small introns may be present that were not detected by restriction mapping. Restriction mapping, as well as sequence analysis of $5^{\prime}$ and $3^{\prime}$ termini, indicate that all of the cDNA clones that we isolated are colinear and that none represent alternatively spliced forms of $H$ mRNA (Fig. $1 \mathrm{~A}_{\text {; }}$ data not shown). Because we isolated only one putative full-length $H$ cDNA clone, however, we cannot rule out the possibility that alternative splicing could contribute to the complexity of $H$ transcripts.

It is interesting to correlate the nature of the disruptions in the $H$ ORF caused by the D179, $H^{18}, H^{20}$, and $H^{22}$ mutations (Fig. 1A) with the severity of the phenotypes conferred by these mutations (Bang et al. 1991). $H^{18}$, a deletion of almost the entire $H$ protein-coding region, and $H^{20}$, a 2-kb inversion with both breakpoints inside the $H$-coding region, behave as null mutations. $H^{22}$, an $\sim 350$-bp deletion that removes at least 19 amino acids from the carboxyl terminus, is a homozygous viable, hypomorphic mutation with a strong $H$ phenotype. The D179 transposon insertion is located in the $5^{\prime}$-untranslated region of the $H$ transcription unit /Figs. 1A and 2; see Materials and methods), yet the resulting mutant phenotype is quite mild. One possible explanation is that a cryptic transcription start site is utilized. This hypothesis is supported by other results presented here, suggesting that neither a fine spatial/temporal regulation of $H$ transcription nor high levels of $H$ transcript accumulation are required for normal $H$ function (see below and Discussion).

\section{Rescue of $\mathrm{H}$ mutant phenotypes in transgenic flies}

To test whether the sequences we had identified as the $H$ gene are capable of rescuing $H$ mutant phenotypes, we constructed a hybrid gene in which a cDNA fragment containing the entire $H$ protein-coding region is fused to the Heat-shock protein $70(\mathrm{Hsp} 70)$ promoter (see Materials and methods). This construct was introduced into flies by P-element-mediated germ-line transformation (Rubin and Spradling 1982), and 12 independent transformant lines were obtained. For 8 of the 12 lines, a single copy of the $\mathrm{P}[\mathrm{Hs}-\mathrm{H}]$ transgene, without the application of heat shock, was sufficient to confer complete rescue of the haploinsufficient phenotype of $H^{2} /+$ heterozygotes; this includes both the double socket and bristle loss defects (Fig. 3A,B). The other four lines gave partial rescue of this phenotype. For both of the independent lines tested $(\mathrm{P}[\mathrm{Hs}-\mathrm{H}]-1$ and $\mathrm{P}[\mathrm{Hs}-\mathrm{H}]-4)$, bristle phenotypes and pupal lethality of $H^{2}$ homozygotes were similarly rescued by a single copy of the $\mathrm{P}[\mathrm{Hs}-\mathrm{H}]$ transposon, again without heat shock induction. Flies of the genotype $H^{2} \mathrm{P}[H s-H]-1 / H^{2}$ are viable and fertile and exhibit a phenotype comparable to that of $H^{2}$ heterozy-

Figure 2. Sequence of $H$ cDNA clones and of the predicted $H$ protein product. Numbers at left represent nucleotides starting from the $5^{\prime}$ end of cDNA clone $2-10$; numbers at right indicate amino acid positions in the predicted $\mathrm{H}$ protein sequence. The genomic DNA sequence is shown in lowercase letters. Positions of the ends of primer extension products are indicated by asterisks $\left({ }^{*}\right)$, and a putative TATA box-like sequence (gatattt) is double underlined (see Fig. 1B). The indicated ATG is probably utilized as the start codon, as this is the first ATG in the long ORF and the sequence ACAACAATG shows similarity to the translation start consensus sequence C/AAAA/CATG; (Cavener 1987). Use of any of the other 13 potential start codons (ATG underlined) within the 685 nucleotides of $5^{\prime}$-untranslated sequence would produce only short peptides. The approximate location of the D179 transposon insertion is indicated by dotted underlining. Six consensus polyadenylation signals (AATAAA, shown in bold; Wickens 1990) appear within the 2043 nucleotides of $3^{\prime}$-untranslated sequence that follows the ORF. Numbered arrowheads $(1-4)$ indicate intron/exon junctions within the cDNA sequence. The Asp 718 and EcoRV restriction site termini of the $H$ cDNA fragment used in the $\mathrm{P}[H s-H]$ construct are indicated. The PRD repeat motif in the $H$ protein is double underlined. The GenBank accession number for the $H$ cDNA sequence is M95192. 
gotes (Fig. 3C,D). Moreover, flies of the genotype $\mathrm{H}^{2}$ $\mathrm{P}[H s-H]-1 / H^{2} \mathrm{P}[H s-H]-1$ are wild type in appearance, except that they still exhibit shortening of the fifth longitudinal wing vein, a characteristic $H$ hypomorphic phenotype (data not shown). It is clear from these experiments that the relatively low level of expression of the $H$ coding region provided by the basal activity of the $H s p 70$ promoter, in the absence of any $5^{\prime}$ regulatory sequences from the $H$ gene, is sufficient to rescue lethality and restore a nearly wild-type phenotype to $H$ mutant flies. In view of the haploinsufficiency of $H$ function, this suggests that wild-type flies have only a low level of $H^{+}$activity.

\section{Sequence of the predicted $H$ protein product}

The $H$ cDNA clone $2-10$ contains a single long ORF of 3177 bases, capable of encoding a protein product of 1059 amino acids with an approximate size of $109 \mathrm{kD}$ (Fig. 2). The most striking property of the deduced $\mathrm{H}$ protein sequence is its highly basic character; positively charged residues are distributed along the entire length of the protein, which has an estimated pI of 9.5. Another distinguishing feature is a region of $>100$ amino acids that is rich in acidic residues and largely overlaps a predicted $\alpha$-helical segment (residues $340-454$ of Fig. 2). This acidic region is flanked on either side by particularly basic regions of the protein. Long homopolymeric runs of alanine residues, especially near the carboxyl terminus, also stand out as unusual characteristics of the predicted $\mathrm{H}$ protein. It is worth noting the strongly skewed amino acid composition of $\mathrm{H}$. Alanine (12.4\%), serine (18.3\%), and proline $(9.4 \%)$ residues comprise $40 \%$ of the predicted sequence.

Comparison of the derived $\mathrm{H}$ amino acid sequence with the GenBank protein data base failed to reveal any extensive homology to other known proteins; however, we found one short segment of $\mathrm{H}$ that is similar to the PRD repeat motif (Frigerio et al. 1986), consisting of alternating histidine and proline residues (Fig. 2). This motif is present in a number of homeo domain proteins from both Drosophila and vertebrates and also in several other types of Drosophila transcription factors, including E74, an ets-related protein; odd-skipped, a zinc-finger protein; and daughterless, a helix-loop-helix protein (for references, see Janknecht et al. 1991). The appearance of the PRD repeat in a variety of known or putative transcriptional regulatory proteins may suggest that $\mathrm{H}$ likewise participates in transcriptional control. The functional significance of this motif, however, is unknown. It
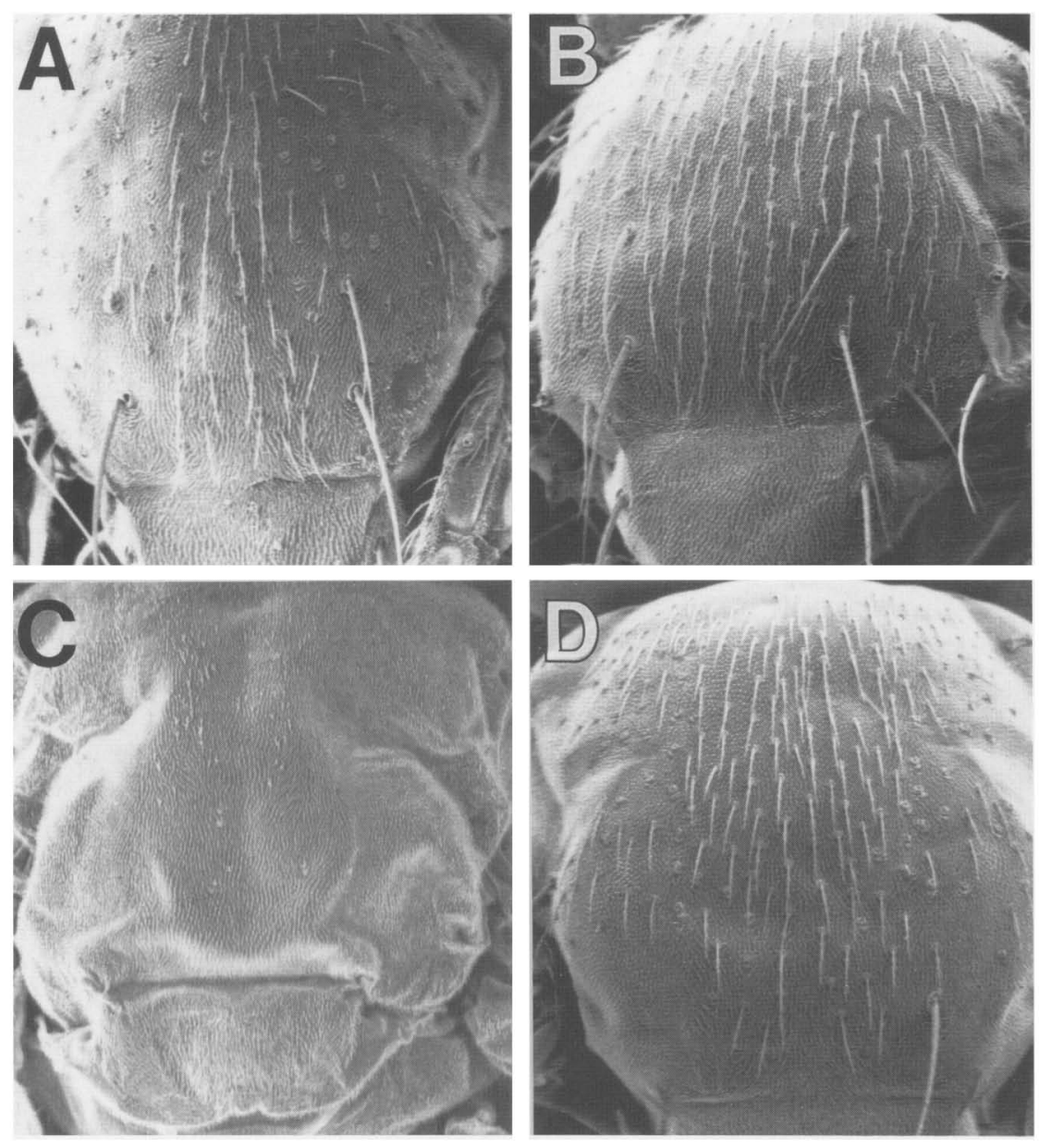

Figure 3. Rescue of $H$ mutant phenotypes in transgenic flies. Scanning electron micrographs of the thoraces of $H$ mutants lacking or carrying a $\mathrm{P}[\mathrm{Hs}-\mathrm{H}]$ transposon insertion. $(A) \mathrm{w}^{1118} ; H^{2} /+.(B) \mathrm{w}^{1118} ; H^{2}$ $\mathrm{P}[H s-H]-1 /+$. (C) $H^{2} / H^{3}$ (animals of this genotype die as pharate adults and must be dissected from the pupal case, resulting in the deformation of the notum). (D) $\mathrm{w}^{1118}$; $H^{2} \mathrm{P}\left[H s-H \mid-1 / H^{2}\right.$. 
has been suggested recently that it may act as a $\mathrm{pH}$ sensitive protein dimerization domain (Janknecht et al. 1991), but as yet, there is no experimental evidence supporting this proposal.

\section{Spatial distribution of $\mathrm{H}$ transcripts}

Because the onset of zygotic transcription occurs $\sim 1.5-2$ hr after egg laying (Edgar and Schubiger 1986), it seemed likely that the $H$ transcripts detected in 0- to 2-hr embryos by Northern blot hybridization (Fig. 1D) are provided maternally. In situ hybridization experiments show specific expression of $H$ in ovarian nurse cells (Fig. 4A). Maternal $H$ transcripts present in syncytial embryos appear to persist until the cellular blastoderm stage (Fig. $4 \mathrm{~B}, \mathrm{Cl}$. The transcript that begins to accumulate during late gastrulation and early germ-band extension (Fig. $4 \mathrm{D}, \mathrm{E}$ ) evidently represents the onset of zygotic $H$ transcription. This interpretation is consistent with the appearance at 4-6 hr of a novel $6.0-\mathrm{kb}$ transcript that is not present at $0-2$ and $2-4 \mathrm{hr}$ (see above and Fig. 1D). These zygotic transcripts are broadly distributed in the embryo throughout germ-band extension and retraction (Fig. 4EG), although initially they appear to accumulate at a somewhat higher level in the mesodermal layer (Fig. 4E); whereas lower levels are consistently observed in parts of the head region, especially the procephalic lobe and the clypeolabrum. These experiments also show that $H$ transcripts are present in the developing CNS at the time of action of the zygotic neurogenic genes, consistent with the suppression by $H$ mutations of the neural hyperplasia caused by loss of neurogenic gene function (Vässin et al. 1985; de la Concha et al. 1988).

Because of the important role played by $H$ in controlling cell fate in the adult PNS (Bang et al. 1991; see introductory section), we were especially interested in examining the spatial pattern of $H$ transcript accumulation in the imaginal discs during the period of sensory organ development. In situ hybridization to imaginal discs of late third-instar larvae, at the time of macrochaete SOP determination (Cubas et al. 1991; Huang et al. 1991; Skeath and Carroll 1991), revealed a widespread, apparently uniform distribution of $H$ transcripts (Fig. 5A). We also examined the pattern of $H$ expression in pupal notum tissue between $14 \mathrm{hr}$ after puparium formation (APF) and $25 \mathrm{hr}$ APF. The macrochaete precursors have completed their divisions by $14 \mathrm{hr} A P F$, and their four progeny have begun differentiating, whereas microchaete SOP cells are just commencing their divisions (Hartenstein and Posakony 1989). Prior to $16 \mathrm{hr}$ APF, $H$ transcripts appear to be uniformly distributed in the notum epithelium, except for a higher level of accumulation in two cells of the developing macrochaetes that persists throughout the period analyzed (see below). By $16 \mathrm{hr}$ APF, higher levels of transcript are detectable in single cells and, possibly, pairs of cells in the positions of the future microchaetes in a background of generalized expression (Fig. 5B). We are unable to determine the identity of these cells, but it is possible that they are the secondary precursors that will generate the trichogen and tormogen because these precursors are present and about to commence their division at this time (Hartenstein and Posakony 1989). This interpretation is consistent with the finding that after $16 \mathrm{hr}$ APF, elevated levels of $H$ transcript are observed in two cells in each developing microchaete (Fig. 5C). From their positions relative to the epidermal plane, and from the apparent size of their nuclei in the macrochaetes, we have identified these cells as the trichogen and tormogen (Fig. 5D). Thus, by $24 \mathrm{hr}$ APF, the differentiating trichogen and tormogen cells of both macrochaetes and microchaetes have accumulated high levels of $H$ RNA (Fig. 5C,D). We were unable to determine in these experiments the state of $H$ expression in the other two cells of the mechanosensory bristles, the neuron and thecogen.

Finally, we carried out in situ hybridization experiments using as a probe a 398-bp fragment of $3^{\prime}$-untranslated sequence that is specific to the $6.0-\mathrm{kb}$ zygotic $H$ transcript. Results similar to those described above were obtained for both embryonic and imaginal disc tissue (data not shown), except that this probe does not detect maternal $H$ expression.

\section{Phenotypic consequences of overexpression of $\mathrm{H}$}

The $\mathrm{P}[H s-H]$ transformant lines described above offered the opportunity to investigate the phenotypic consequences of overexpression of $H$. This was of particular interest to us, because hypermorphic alleles of $H$ have not been described. Animals homozygous for either $\mathrm{P}[\mathrm{Hs}-\mathrm{H}]-3$ or $\mathrm{P}[\mathrm{Hs}-\mathrm{H}]-4$ were subjected to a heat shock induction regimen as third-instar larvae, white prepupae, or 14- to 24-hr pupae. These stages span the period of SOP determination, SOP division, and sensillum cell fate determination in the adult PNS (Hartenstein and Posakony 1989, 1990; Cubas et al. 1991; Huang et al. 1991; Skeath and Carroll 1991). The adult flies that developed from heat-shocked animals exhibited a number of striking phenotypic effects (Fig. 6). On many of these flies, a large number of mechanosensory bristles in their normal positions exhibited a nearly identical phenotype in which two bristle shafts project from the cuticular surface, and no socket appears (Fig. 6D,E,I,I). Both of the shafts are well formed and display the characteristic fluted shape. Because a second shaft appears in the double shaft bristles at the expense of the bristle socket, we interpret this defect as a tormogen-to-trichogen cell fate transformation; that is, the opposite transformation from that which underlies the $H$ hypomorphic double socket phenotype (Fig. 6F). In addition to the double shaft effect, adult flies developing from heat-shocked $\mathrm{P}[H s-H]$ larvae and pupae also exhibited a high frequency of multiplication and/or loss of microchaetes or macrochaetes (Fig. 6A-C,G-I). These phenotypes strongly mimic those caused by loss-of-function mutations of the neurogenic genes (Shellenbarger and Mohler 1978; Dietrich and Campos-Ortega 1984; Hartenstein and Posakony 1990). In the case of the temperature-sensitive $N$ allele $N^{t s 1}$ (Shellenbarger and Mohler 1978), the developmental bases of the bristle multiplication and loss effects 


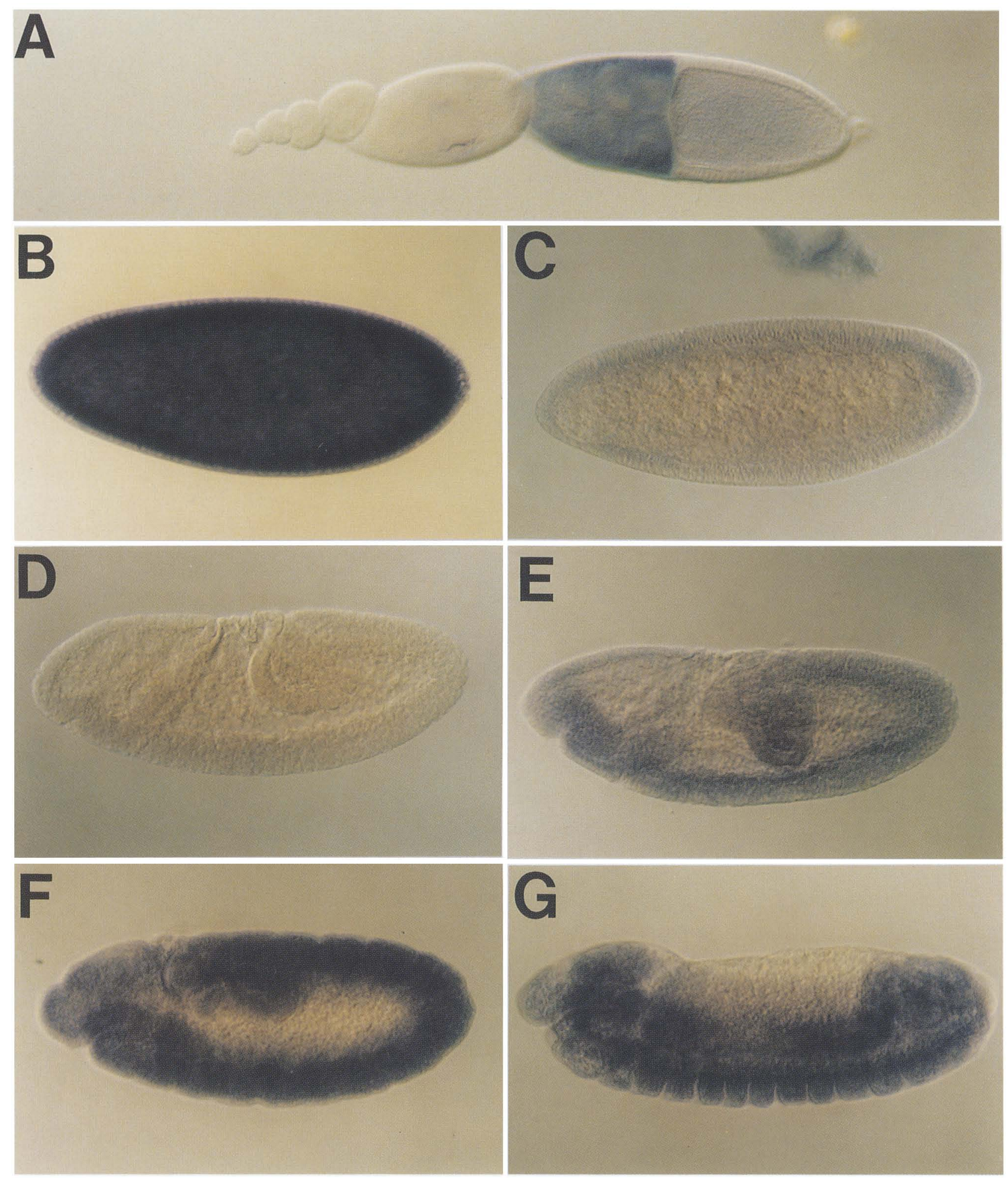

Figure 4. Localization of $H$ transcripts in ovaries and developing embryos. Whole-mount preparations of a wild-type ovariole $|A|$ and staged wild-type embryos $(B-G)$ hybridized in situ with an antisense $H$ RNA probe labeled with digoxygenin. Micrographs were made with Nomarski optics. In $B-G$, anterior is to the left and dorsal is at the top. $(A)$ Germ line-specific expression in nurse cells of a stage 10 egg chamber. A very low level of $H$ expression is first observed in stage $7-8$ egg chambers (data not shown). In bright-field images, low levels of transcript are also detected in follicle cells. Embryonic stages are as follows (Campos-Ortega and Hartenstein 1985): $(B)$ late pre-cellular blastoderm; $\{C \mid$ late cellular blastoderm; $(D)$ stage $8 ;(E)$ stage $9 ;(F)$ stage $11 ;(G)$ stage 14 . 
Figure 5. Localization of $H$ transcripts in the wing imaginal disc and in pupal nota. Whole-mount preparations were hybridized in situ with an antisense $H$ RNA probe labeled with digoxygenin. $(A)$ Wing imaginal disc from a late third-instar larva. (B) Pupal notum dissected at $16 \mathrm{hr}$ APF. Arrows indicate faint but reproducible hybridization to cells distributed in the microchaete pattern. (C) Pupal notum dissected at $24 \mathrm{hr}$ APF. (D) High-magnification view of a pupal head dissected at $24 \mathrm{hr}$ APF, showing two macrochaetes in which the trichogen $(\mathrm{tr})$ and tormogen (to) cells are slightly offset to illustrate the hybridization of the $H$ probe to both of these cells. In the wild-type bristle, the trichogen lies directly underneath the tormogen; occasionally in mounted preparations, both cells can be seen in the same plane, as here.
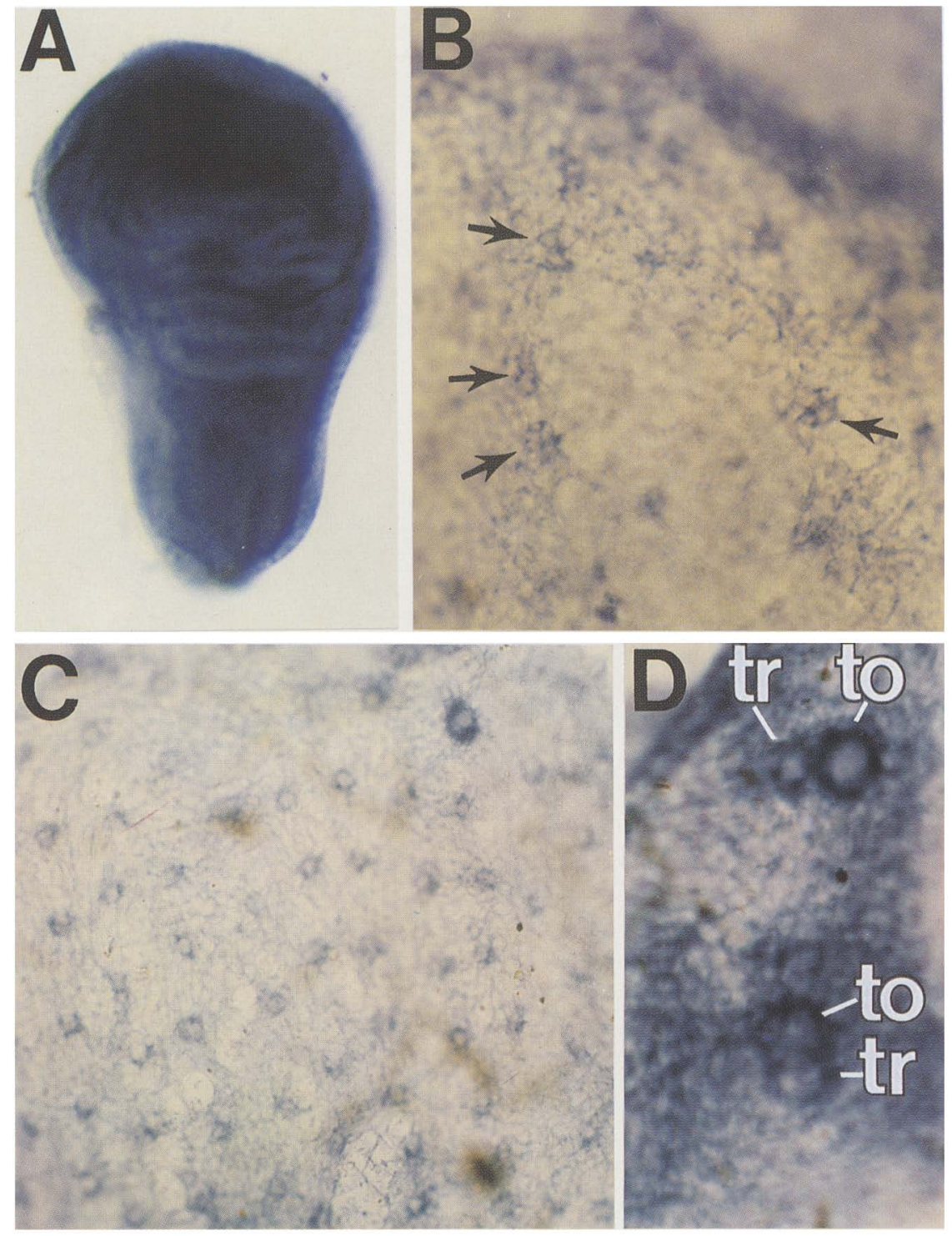

have been investigated in detail (Hartenstein and Posakony 1990). They result from overcommitment of cells in the imaginal disc to the SOP cell fate at the expense of the epidermal cell fate, and overcommitment of SOP progeny cells to the sensory neuron fate at the expense of accessory cell fates, respectively. We believe it is likely that the same developmental defects underlie these phenotypes in the $\mathrm{P}[H s-H]$ animals. The ability of $H$ overexpression to phenocopy neurogenic loss-of-function effects in otherwise wild-type animals is entirely consis-

Figure 6. Phenotypic consequences of overexpression of $H \cdot(A-C)$ Scanning electron micrographs of the ocellar region of the heads of homozygous $\mathrm{P}[H s-H]-3$ adults, either unshocked $\langle A|$ or heat-shocked at the late third-instar larva/white prepupa stage $(B-C) .(D-F)$ Scanning electron micrographs of postvertical macrochaetes of the head. (D) Symmetrical double shaft (no socket) phenotype from a homozygous $\mathrm{P}[H s-H]-3$ pharate adult heat-shocked as a late third-instar larva/white prepupa. $(E)$ Normal macrochaete from an unshocked $\mathrm{P}[H s-H]-3$ animal. $(F)$ Double socket phenotype of a $H$ loss-of-function mutant $\left(w^{1118} ; H^{2} /+\right)$. $(G-K)$ Light micrographs of nota dissected from homozygous $\mathrm{P}[H s-H]-3$ pharate adults heat-shocked at the following times: $(G)$ unshocked $(H)$ late third-instar larva/white prepupa; (I) $14 \mathrm{hr}$ APF; $(I) 24 \mathrm{hr}$ APF; $(K) 20 \mathrm{hr}$ APF. Examples of bristle multiplication are shown in $B$ (increased number of interocellar microchaetes) and $H$ (increased microchaete density). The bristle loss phenotype is shown in $C$ (arrow shows the normal position of a missing postvertical macrochaete) and $I$. In $I$, the notum has a normal complement of microchaetes, many of which exhibit double shaft phenotypes. The presutural macrochaete shown in $K$ illustrates the unusual asymmetric double shaft phenotype induced by heat shocks late in macrochaete development (see text for description). The arrow indicates what appears to be a socket-like structure. Note also an additional shaft-like structure projecting from the base of this macrochaete. 

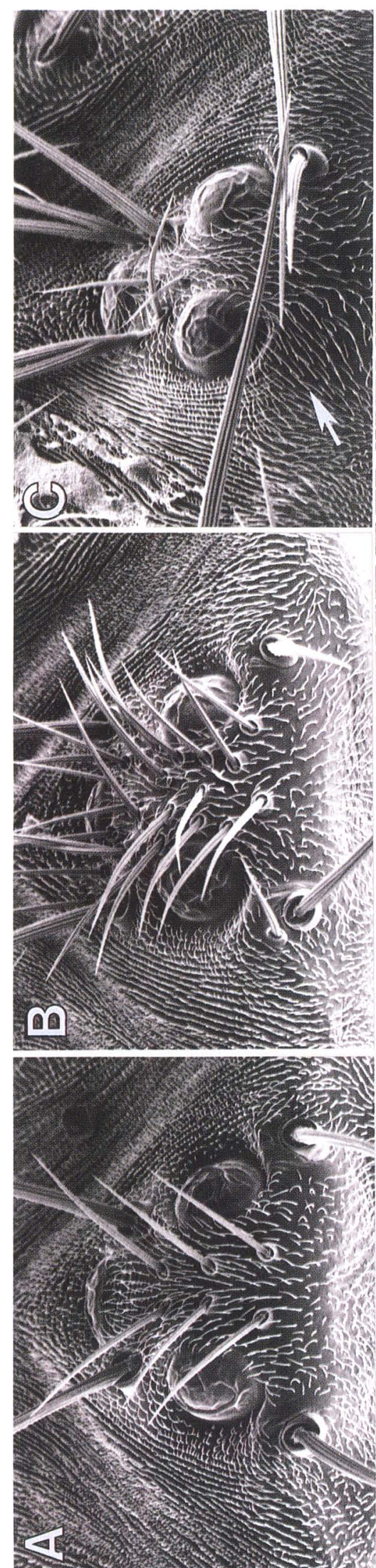
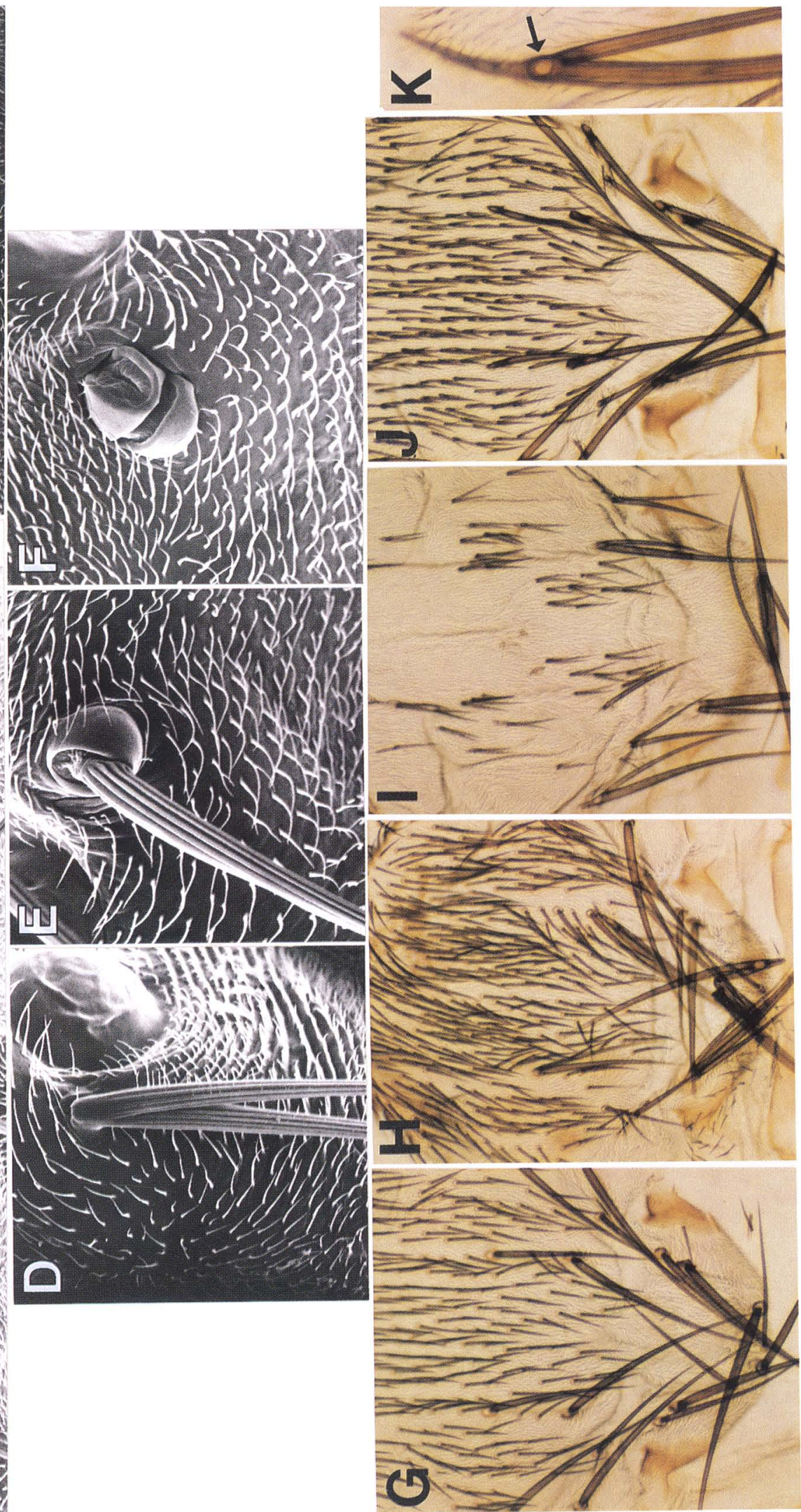

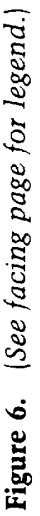


tent with the many previous observations that loss of $H$ function suppresses neurogenic phenotypes (see introductory section). Thus, our results appear to provide additional evidence that $\mathrm{H}^{+}$is a potent antagonist of neurogenic gene activity during sensory organ development.

Further support for our developmental interpretation of these $\mathrm{P}[\mathrm{Hs}-\mathrm{H}]$ phenotypes was obtained by correlating the time of heat shock treatment with the frequency of each phenotype as exhibited by microchaetes in the treated animals. Heat shocks commenced at the late third-instar larval and white prepupal stages, spanning the period of microchaete SOP determination, resulted in the microchaete multiplication phenotype in the adult (Fig. 6H). Virtually all of the individual microchaetes in these animals have a normal shaft and socket, suggesting that the phenotype is the result of determination of supernumerary microchaete SOPs, which then develop normally. In contrast, heat shocks initiated at 14 $\mathrm{hr}$ APF and spanning the period during which the microchaete SOPs divide and their progeny commence differentiation, resulted in adults with a massive loss of microchaetes (Fig. 6I). Those few microchaetes that remain are of the double shaft type, suggesting that the microchaete loss effect results from a failure of proper microchaete cell differentiation and not from a defect in SOP determination. Finally, heat shocks starting at $24 \mathrm{hr}$ APF and spanning the later period of microchaete cell differentiation resulted in adults with a normal complement of microchaetes, of which roughly half exhibited double shaft phenotypes (Fig. 6J).

Interestingly, we found that heat shocks administered as late as $14-20 \mathrm{hr}$ APF resulted in adults with a low frequency of unusual double shaft macrochaetes (Fig. $6 \mathrm{~J}, \mathrm{~K})$. These bristles have a very characteristic appearance (Fig. $6 \mathrm{~K}$ ) that is distinct from the symmetrical double shaft phenotype described above. At the base of a relatively normal macrochaete shaft, we observe a ringlike structure from which projects a second shaft that is thinner and shorter. Many of these late double shaft macrochaetes also have additional shaft-like structures projecting from the base. This result was unexpected, because by 14-20 hr APF, the individual cells of the macrochaetes are well into their differentiation program (Hartenstein and Posakony 1989). Our interpretation is that the tormogen cell is able to initiate shaft development in response to overexpression of $H$ even after it has begun differentiating a socket-like structure.

\section{Discussion}

\section{Sequence of the predicted $H$ protein}

The presence of a $(\mathrm{HX})_{n} \mathrm{PRD}$ repeat motif (Frigerio et al. 1986) near the carboxyl terminus of the predicted H protein (Fig. 2) is of interest for two reasons. First, this motif is not only present in a number of Drosophila homeo domain proteins, but it is conserved in a number of homologous vertebrate homeo domain proteins as well. Second, the PRD repeat has been described in several other types of Drosophila transcription factors, including an ets-related protein, E74; a zinc-finger protein, oddskipped; and a helix-loop-helix protein, daughterless. That both the $\mathrm{H}$ and daughterless proteins contain this motif is especially noteworthy, because both are required for the specification and/or execution of the SOP cell fate during PNS development /Caudy et al. 1988; Bang et al. 1991). Though both its highly basic character and the presence of the PRD repeat motif are consistent with the possibility that $\mathrm{H}$ may be a nuclear protein that interacts with DNA, its subcellular localization remains to be determined.

\section{Expression and function of $\mathrm{H}$}

Our previous study revealed that $H$ plays an essential role in the specification and/or execution of the SOP cell fate in imaginal discs (Bang et al. 1991). The apparently ubiquitous accumulation of $H$ transcripts in imaginal discs at the time of macrochaete SOP determination (Fig. $5 \mathrm{~A}$ ) and in pupal nota at the time of microchaete SOP determination (14 hr APF; data not shown) suggests that this function does not require spatially localized $H$ transcription. Consistent with this conclusion is the observation that $H$ expression driven by the basal activity of the $H s p 70$ promoter is capable of rescuing the $H$ null bristle loss phenotype (Fig. 3C,D). We have observed elevated levels of $H$ expression in at least one cell during the microchaete precursor divisions (16 hr APF; Fig, 5B), consistent with the role of $H$ activity in controlling the fates of the trichogen and tormogen sister cells /see below). Here again, Hsp70-driven expression is sufficient to restore this function to $H$ null animals, because many normal bristles are present in the rescued adult flies (Fig. 3D). These results suggest that differential $H$ activity in different cells is controlled post-transcriptionally. Our experiments have also revealed the persistence of relatively high levels of $H$ transcript in the trichogen and tormogen cells of the pupal notum after they have commenced their differentiation (Fig. 5B-D). The function of this expression is unclear at present; perhaps it has a role in maintaining the socket and shaft fates.

We also found that $H$ is expressed zygotically in the embryo, again in a very broad pattern (Fig. 4E-G). Animals that are genotypically null for $H$ survive embryogenesis at high frequency, indicating that there is no obligatory embryonic requirement for zygotic $H$ activity (Bang et al. 1991). Nevertheless, expression of $H$ at this stage was expected because $H$ mutations have been reported to suppress the embryonic neural hyperplasia caused by loss-of-function alleles of the neurogenic genes N,Dl, mam, and neu (Vässin et al. 1985; de la Concha et al. 1988). $H$ transcripts are present in the developing CNS at the time of neuroblast segregation (Fig. $4 \mathrm{E}, \mathrm{F})$. Our observation that $H$ is expressed maternally (Fig. 4A,B) raises the possibility that $H$ may have an important embryonic function but that maternally supplied $\mathrm{H}^{+}$activity is sufficient to allow the development of zygotically null embryos. 
The level of $\mathrm{H}$ activity controls the expression of alternative fates by the trichogen and tormogen cells

The $H$ double socket phenotype provides a clear demonstration of the requirement for $\mathrm{H}^{+}$function in controlling the expression of alternative cell fates by the trichogen/tormogen sister cell pair. Previous studies have examined this phenotype in detail (Lees and Waddington 1942; Bang et al. 1991). The fate of the trichogen (shaft) cell is very sensitive to the level of $H^{+}$activity; even a reduction of $\mathrm{H}^{+}$gene dosage from two to one las in a $H$ null heterozygote) is sufficient to cause in many macrochaete bristles a transformation of this cell into a second tormogen (socket) cell. Thus, a certain threshold level of $\mathrm{H}^{+}$activity is necessary for the specification and/or expression of the trichogen (shaft) cell fate; when the level of $\mathrm{H}^{+}$activity drops below that threshold, both sister cells adopt the tormogen (socket) fate. Conversely, both macrochaete and microchaete bristles exhibit a striking double shaft phenotype at high frequency when transgenic animals carrying the $\mathrm{P}[\mathrm{Hs}-\mathrm{H}]$ construct are subjected to heat shock as late third-instar larvae and pupae.

Taken together, these results strongly suggest that the expression of distinct cell fates by the trichogen/tormogen sister cell pair depends on an asymmetry in their levels of $H^{+}$activity or in their thresholds for response to $H$. According to this model (Fig. 7), in the wild-type fly the trichogen (shaft) cell has a higher level of $\mathrm{H}^{+}$activity (or a lower response threshold), whereas the tormogen (socket) cell has a lower level of $H^{+}$(or a higher response threshold). In the $H$ hypomorphic mutant, both sister cells have a low level of $\mathrm{H}^{+}$and, consequently, both adopt the tormogen (socket) fate; conversely, in the $\mathrm{P}[H s-H]$ animals, both sisters have a high level of $H^{+}$and both express the trichogen (shaft) fate. Thus, the hypoand hyperactivity of $H$ can cause a normally asymmetric cell division to yield both of the possible symmetric cell fate outcomes. A similar phenomenon has been observed in the case of the yeast gene SWI5 (Nasmyth et al. 1987; for review, see Horvitz and Herskowitz 1992). The division of a wild-type yeast cell generates one progeny cell that is capable of undergoing mating-type interconversion and one cell that is not. Division of a SWI5 - mutant produces two nonswitching cells, whereas ectopic expression of SWI5 in the normally nonswitching cell permits both progeny to undergo mating-type conversion.

Recent studies in our laboratory have provided evidence that the gene Suppressor of Hairless $[\mathrm{Su}(\mathrm{H})]$ may be responsible for controlling $\mathrm{H}^{+}$activity in the trichogen and tormogen cells. Loss-of-function alleles of $\mathrm{Su}(H)$ act as dominant suppressors of the $H$ double socket phenotype, whereas a gain-of-function allele is a dominant enhancer of this phenotype (Nash 1965, 1970; Ashburner 1982). We have found that transgenic flies carrying several extra copies of the wild-type $S u(H)$ gene exhibit a fully penetrant double socket effect indistinguishable from that observed in $H$ mutants, and that $\mathrm{Su}(H)$ transcripts are specifically expressed in the shaft and socket cells, as are $H$ transcripts (Schweisguth and Posakony 1992).
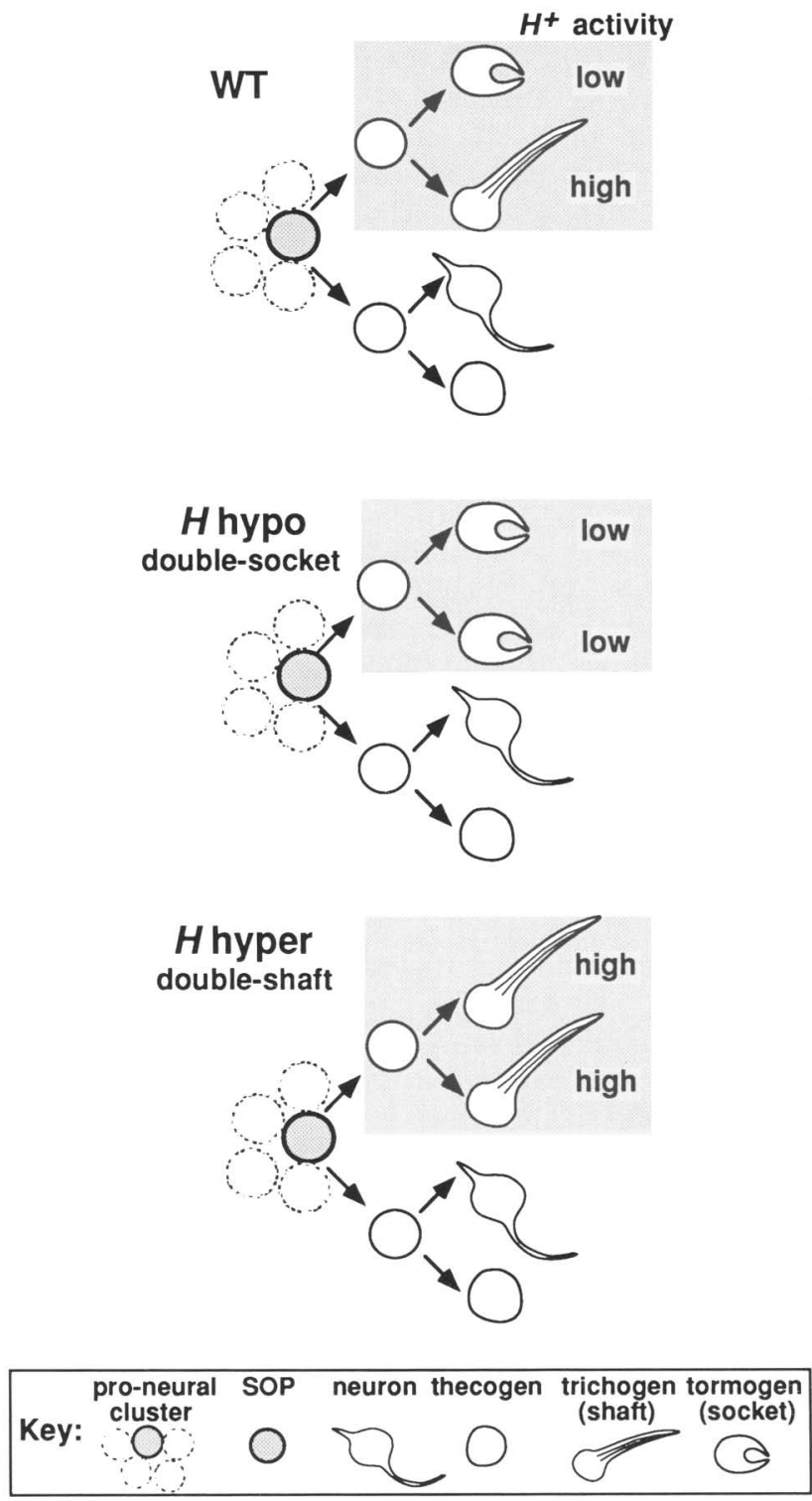

Figure 7. Activity of $H$ in controlling the trichogen and tormogen cell fates. Illustration of the phenotypic consequences to the trichogen (shaft) and tormogen (socket) cells of a mechanosensory bristle when $H^{+}$activity is either reduced by mutation ( $H$ hypo) or increased by overexpression ( $H$ hyper), as compared with wild type (WT). In the case of the double shaft phenotype, we have represented the neuron and thecogen cells as differentiating normally; further experiments are necessary to demonstrate this.

\section{Overexpression of $\mathrm{H}$ causes neurogenic phenotypes}

In addition to their phenotypic effects in otherwise wildtype flies (see Bang et al. 1991), $H$ mutations have been shown to exhibit phenotypic interactions with mutant alleles of the neurogenic genes $N, D l, E(s p l)$, neu, and mam. $H$ loss-of-function alleles suppress the phenotypic effects of neurogenic loss-of-function mutations and enhance the effects of gain-of-function alleles (see intro- 
ductory section). These results are consistent with a role for $H$ as a negative regulator of one or more of the neurogenic genes (Vässin et al. 1985; de la Concha et al. 1988). Accordingly, one might have predicted that an excess of $\mathrm{H}^{+}$activity would result in super-repression of neurogenic gene activity, effectively producing phenotypes similar to those caused by loss-of-function mutations in these genes [although it has been reported that flies carrying four copies of the $H$ locus appear wild type in phenotype [Vässin et al. 1985)]. The $\mathrm{P}[\mathrm{Hs}-\mathrm{H}]$ transformant lines that we established offered the opportunity to assay directly the phenotypic consequences of overexpression of the $H$ gene product.

$\mathrm{P}[\mathrm{Hs}-\mathrm{H}]$ transgenic animals subjected to heat shock treatment during late third-instar larval and early pupal stages exhibit adult phenotypes that strongly resemble those described for the temperature-sensitive $N$ allele $N^{t s 1}$, including both multiplication and loss of macrochaete and microchaete bristles on the head and thorax (Fig. 6). The developmental basis for these phenotypes has been described in detail for $N^{t s 1}$ (Hartenstein and Posakony 1990). A heat pulse applied to $N^{\text {ts } 1}$ animals from 0-12 hr APF, before the onset of the microchaete SOP cell divisions, leads to an increase in these SOPs at the expense of epidermal cells, resulting in the appearance of multiplied and tufted microchaete bristles on the adult fly. A later heat pulse from 12-24 hr APF, during and after the microchaete SOP divisions, leads to hyperplasia of sensory neurons at the expense of microchaete accessory cells. This causes an adult bristle loss phenotype, because the affected sensilla lack the trichogen and tormogen cells that would normally produce the external cuticular structures of the bristle. These observations suggested that similar $N$-dependent inhibitory cell-cell interaction mechanisms may be operating to select a single SOP within the proneural cluster and a single sensory neuron from the four progeny of the SOP (Hartenstein and Posakony 1990). It should be noted that the same developmental defects described above have been demonstrated to underlie the bristle multiplication and loss phenotypes caused by a temperature-sensitive allele of the neurogenic gene DI (A. Parks and M. Muskavitch, pers. comm.) and by the dominant mutation Bearded (Brd; M. Leviten and J.W. Posakony, unpubl.). Additional studies will be required to establish the cellular bases of the neurogenic phenotypes in the $\mathrm{P}[H s-H]$ animals, but it is reasonable to conjecture that they will also be similar to those for $N^{t s 1}$, reflecting an interference with inhibitory cell-cell interactions.

Integrating the $H$ loss-of-function phenotype (Bang et al. 1991), the genetic interactions of $H$ with the neurogenic genes (see introductory section) and the bristle multiplication phenotype of the P $[H s-H]$ flies (Fig. 6) allows us to propose a working hypothesis for the role of $H$ in SOP determination. We suggest that $H$ serves to protect the SOP cell from lateral inhibition by antagonizing neurogenic gene activity in this cell. Thus, $H$ would normally be active or effective only in the presumptive SOP; loss of $H$ function would cause this cell to adopt an epidermal fate, like the other cells in the proneural cluster (the $H$ bristle loss phenotype; Bang et al. 1991). Conversely, overexpression of $H$ would interfere with neurogenic gene activity in many or all of the cells in the cluster, resulting in the failure of lateral inhibition and the assumption of the SOP fate by multiple cells (the $\mathrm{P}[$ Hs- $H]$ bristle multiplication/tufting phenotype; Fig. 6). The finding that $H$ loss-of-function mutations are potent suppressors of the bristle multiplication phenotypes of both Brd and $N^{s 1}$ (A.G. Bang and J.W. Posakony, unpubl.) is consistent with this hypothesis and indicates that ectopic SOPs, like the normal single SOP, require $H^{+}$activity for their expression of the SOP fate. Our model requires that the spatial pattern of proneural clusters is established normally in $\mathrm{H}^{-}$mutants. In situ hybridization experiments reveal a normal spatial distribution of both achaete and scute transcripts in $H$ null imaginal discs (A.G. Bang and J.W. Posakony, unpubl.).

It is clear from the evidence cited above that at least $N$ and $D l$ play an essential role in establishing the fates of the presumptive sensillum cells, perhaps by mediating cell-cell interactions akin to those occurring in the proneural cluster (Hartenstein and Posakony 1990). Thus, it is possible that the function of $H$ at this later stage of sensory organ development (including controlling the expression of the trichogen and tormogen cell fates) likewise involves negatively regulating neurogenic gene activity. Recently, we have found (A.G. Bang and J.W. Posakony, unpubl.) that $H$ loss-of-function mutations suppress the bristle loss phenotype of $N^{t s 1}$, in which all of the progeny of the SOP differentiate as sensory neurons. This is consistent with the idea that $H$ normally antagonizes neurogenic gene activity in the sensory neuron. In this view, the sensory neuron would require $\mathrm{H}^{+}$ activity to protect it from inhibitory cell-cell interactions that ensure the emergence of a single neuronal cell from the four progeny of the SOP. The bristle loss phenotype observed in $\mathrm{P}[H s-H]$ flies (Fig. 6C,I) would result from this same activity being extended to all four cells. As we have noted earlier (Bang et al. 1991), we do not know whether the $H$ double socket phenotype represents the null condition for the function of $H$ in sensillum cell fate determination. Complete loss of $\mathrm{H}^{+}$activity at this point in sensory organ development might result in cell fate defects beyond a trichogen-to-tormogen transformation, including the failure of sensory neurons to appear.

\section{Materials and methods}

Drosophila stocks

Flies were raised on standard yeast/cornmeal/molasses/agar media at $25^{\circ} \mathrm{C}$. Except for D 179 (see below), mutant alleles of $H$ (3-69.5) used in this study are described in Lindsley and Zimm (1992) and in Bang et al. (1991). We have found that the $H$ alleles $\mathrm{H}^{21}$ (designated $H^{\mathrm{C} 23}$ in Bang et al. 1991) and $H^{22}$ (designated $H^{R P I}$ in Bang et al. 1991) carry the same molecular lesion in the $H$ gene (data not shown). Thus, it is likely that $\mathrm{H}^{21}$ and $H^{22}$ are the same allele and were not derived from independent mutagenic events. All other mutations and chromosomes used in this study are described in Lindsley and Zimm (1992). 


\section{General molecular biology procedures}

Basic techniques not described in detail below are described in Maniatis et al. (1982) and in Ausubel et al. (1987).

\section{DNA and RNA isolation}

Genomic DNA and total RNA were isolated as described in Ellis et al. (1990). Poly(A) ${ }^{+}$RNA was isolated using the PolyATtract kit (Promega) according to the manufacturer's instructions.

\section{Isolation of $\mathrm{H}$ genomic DNA}

Plasmid rescue was performed with the D179 transposon insertion line, as described (Pirrotta 1986). The $\mathrm{P}\left[{\operatorname{lac} Z, \mathrm{w}^{+} \mid \text {enhancer }}^{+}\right.$ trap transposon has been described (Bier et al. 1989). One of the plasmid rescue clones recovered was used to probe the CoSpeR iso-1 cosmid genomic DNA library (kindly provided by J. Tamkun|, and 17 clones with approximate insert sizes of $45 \mathrm{~kb}$ were recovered by standard procedures.

\section{Analysis of allele-specific molecular lesions}

A panel of cytologically normal $H$ alleles induced in a $\gamma$-ray mutagenesis of a Brd $p^{p}$ chromosome (see Bang et al. 1991) was screened for molecular lesions in the $H$ gene by Southern blot hybridization analysis (see text). The $H^{22}$ lesion deletes a 304-bp genomic SpeI fragment, indicating that at least 19 amino acid residues are removed from the carboxyl terminus of the $\mathrm{H}$ protein in this mutant. The location of the D179 transposon insertion was determined by sequence analysis of the plasmid rescue clones with an oligonucleotide primer specific for the P-element "feet".

\section{Primer extension and RNase protection analyses}

Primer extension and RNase protection analyses were performed essentially as in Ausubel et al. (1987). For primer extension experiments, an oligonucleotide complementary to nucleotides 126-151 of the $H$ cDNA sequence (Fig. 2) was used. A gel marker was generated by sequencing genomic DNA with the primer extension oligonucleotide as a primer. For RNase protection experiments, a 390-bp RsrII (+121)-EcoRI $1-269$ ) genomic DNA fragment (see Fig. 2) was subcloned into the pBluescript KS( + ) vector (Stratagene) to derive the pRsr plasmid. This subclone was cleaved with HindIII (which cuts within the insert fragment), and an antisense RNA probe of 297 nucleotides was transcribed with T7 RNA polymerase and $\left[{ }^{32} \mathrm{P} \mid \mathrm{CTP}\right.$. The RsrIIEcoRI subclone was sequenced from the SK primer site and used as a marker. Two complications arise in the determination of the exact size of the fragments protected by RNase. First, the SK sequencing primer anneals at a site 4 nucleotides removed from the subclone insertion site. Second, there is an inaccuracy inherent in using a DNA marker for an RNA fragment, in that RNA has a higher mobility in denaturing polyacrylamide gels than DNA of the same size, introducing a 5-10\% error in the calculated size of the RNA (Ausubel et al. 1987). Taking these two factors into account, the protected fragments migrated a maximum of 16 nucleotides smaller than their actual size [4 nucleotides $+(10 \%$ of 121 nucleotides $)=16$ nucleotides $)$. If 16 nucleotides are added to the sizes of the fragments protected from RNase, then they are in good agreement with the sizes of the primer extension products.
DNA sequencing

cDNA clones and cosmid clones of genomic DNA were subcloned in the Bluescript $\mathrm{KS}$ ( + | vector (Stratagene) for sequencing. Sequencing was performed as described in Ellis et al. (1990) All reported sequence was determined on both strands.

\section{Analysis of DNA sequences}

DNA sequence data were stored, manipulated, and analyzed by use of DNA Strider (Marck 1988) and MacVector (International Biotechnologies| software.

\section{In situ hybridization}

In situ hybridization to whole embryos was performed essentially as described by Tautz and Pfeifle (1989), with modifications by Jiang et al. (1991). Fixation of imaginal discs and pupal tissue was performed as described (Schweisguth and Posakony 1992), and the hybridization procedure was the same as for embryos. In situ hybridization to ovaries was performed as described (Suter and Steward 1991). Antisense RNA probes, labeled with digoxygenin-UTP, were prepared exactly as described by the manufacturer (Boehringer Mannheim).

\section{Germ-line transformation}

P-element-mediated germ-line transformation was carried out according to Rubin and Spradling (1982). The CaSpeR-Hsp70 transformation vector and the $\mathrm{pHs}-\mathrm{H}$ plasmid were constructed as follows (additional details available on request). Along with 404 bp of the Drosophila Hsp 70 gene promoter (including 200 bp of $5^{\prime}$-flanking sequencel, $850 \mathrm{bp}$ of $3^{\prime}$-untranslated sequence (including a polyadenylation signall from the SV40 T antigen gene was cloned between the PstI and EcoRI sites of the CaSpeR transformation vector (Pirrotta 1988). The resulting vector (CaSpeR-Hsp 70) contains a unique $\mathrm{XbaI}$ cloning site between the $H s p 70$ promoter and the SV40 3 '-untranslated sequence. A 4.08-kb Asp718-EcoRV fragment, isolated from the $H$ cDNA clone 2-10 (see Fig. 2), was blunt end cloned into the $\mathrm{XbaI}$ site of this vector to derive the $\mathrm{pHs}-\mathrm{H}$ plasmid.

\section{Heat shock treatment}

Crawling third-instar larvae, white pre-pupae, or staged pupae were placed in a humid chamber and subjected to a heat shock regimen consisting of three $1-\mathrm{hr}$ exposures at $37^{\circ} \mathrm{C}$ separated by 2-hr intervals at $25^{\circ} \mathrm{C}$ (Rodriguez et al. 1990). Animals were then returned to $25^{\circ} \mathrm{C}$ and allowed to develop. Animals that developed to the pharate adult stage but did not eclose were manually removed from the pupal case. Animals were examined either by scanning electron microscopy (Bang et al. 1991) or by light microscopy. Specimens were dissected and then prepared for light microscopy by treatment with a $1: 1$ mixture of Hoyer's solution (Ashburner 1989) and lactic acid at $65^{\circ} \mathrm{C}$ for $\mathrm{l} \mathrm{hr}$ before mounting on a microscope slide in the same mixture.

\section{Acknowledgments}

The D179 stock was a generous gift of Dr. Maurice Kernan and was identified by Robert Kreber in the laboratory of Dr. Barry Ganetsky. We are grateful to I. Tamkun for providing a cosmid genomic DNA library, and to N. Brown for providing cDNA libraries. We thank G. Schnitzler for constructing the CaSpeRHsp70 vector, J. Margolis for performing the ovary in situ hybridization experiment, and R. Doolittle for advice about pro- 
tein sequence analysis. Excellent technical assistance was provided by D. Pasternak. We wish to thank F. Schweisguth, J. Margolis, and M. Leviten for critical reading of the manuscript. This work was supported by a Pew Scholars award to J.W.P. and by a grant from the National Institutes of Health.

The publication costs of this article were defrayed in part by payment of page charges. This article must therefore be hereby marked "advertisement" in accordance with 18 USC section 1734 solely to indicate this fact.

\section{References}

Ashburner, M. 1982. The genetics of a small autosomal region of Drosophila melanogaster containing the structural gene for alcohol dehydrogenase. III. Hypomorphic and hypermorphic mutations affecting the expression of Hairless. Genetics 101: 447-459.

1989. Drosophila: A laboratory handbook. Cold Spring Harbor Laboratory Press, Cold Spring Harbor, New York.

Ausubel, F.M., R. Brent, R.E. Kingston, D.D. Moore, J.G. Seidman, J.A. Smith, and K. Struhl. 1987. Current protocols in molecular biology. Wiley/Greene, New York.

Bang, A.G., V. Hartenstein, and J.W. Posakony. 1991. Hairless is required for the development of adult sensory organ precursor cells in Drosophila. Development 111: 89-104.

Bier, E., H. Vässin, S. Shepherd, K. Lee, K. McCall, S. Barbel, L. Ackerman, R. Carretto, T. Uemura, and E. Grell. 1989. Searching for pattern and mutation in the Drosophila genome with a P-lac $Z$ vector. Genes \& Dev. 3: 1273-1287.

Brown, N.H. and F.C. Kafatos. 1988. Functional cDNA libraries from Drosophila embryos. J. Mol. Biol. 203: 425-437.

Campos-Ortega, J.A. and V. Hartenstein. 1985. The embryonic development of Drosophila melanogaster. Springer-Verlag, Berlin, Germany.

Caudy, M., H. Vässin, M. Brand, R. Tuma, L.Y. Jan, and Y.N. Jan. 1988. The maternal sex determination gene daughterless has zygotic activity necessary for the formation of peripheral neurons in Drosophila. Genes \& Dev. 2: 843-852.

Cavener, D.R. 1987. Comparison of the translational start sites in Drosophila and other vertebrates. Nucleic Acids Res. 15: 1353-1361.

Corden, I., B. Wasylyk, A. Buchwalder, P. Sassone-Corsi, C. Kedinger, and P. Chambon. 1980. Promoter sequences of eukaryotic protein-coding genes. Science 209: 1406-1413.

Cubas, P., J.-F. de Celis, S. Campuzano, and J. Modolell. 1991. Proneural clusters of achaete-scute expression and the generation of sensory organs in the Drosophila imaginal wing disc. Genes \& Dev. 5: 996-1008.

de la Concha, A., U. Dietrich, D. Weigel, and J.A. CamposOrtega. 1988. Functional interactions of the neurogenic genes of Drosophila melanogaster. Genetics 118: 499-508.

Dietrich, U. and J.A. Campos-Ortega. 1984. The expression of neurogenic loci in the imaginal epidermal cells of Drosophila melanogaster. I. Neurogen. 1: 315-332.

Edgar, B.A. and G. Schubiger. 1986. Parameters controlling transcriptional activation during early Drosophila development. Cell 44: 871-877.

Ellis, H.M., D.R. Spann, and J.W. Posakony. 1990. extramacrochaetae, a negative regulator of sensory organ development in Drosophila, defines a new class of helix-loop-helix proteins. Cell 61: 27-38.

Frigerio, G., M. Burri, D. Bopp, S. Baumgartner, and M. Noll. 1986. Structure of the segmentation gene paired and the Drosophila PRD gene set as part of a gene network. Cell 47: 735-746.
Hartenstein, V. and J.W. Posakony. 1989. Development of adult sensilla on the wing and notum of Drosophila melanogaster. Development 107: 389-405.

- 1990. A dual function of the Notch gene in Drosophila sensillum development. Dev. Biol. 142: 13-30.

Horvitz, R.H. and I. Herskowitz. 1992. Mechanisms of asymmetric cell division: Two Bs or not two Bs, that is the question. Cell 68: 237-255.

Huang, F., C. Dambly-Chaudière, and A. Ghysen. 1991. The emergence of sense organs in the wing disc of Drosophila. Development 111: 1087-1095.

Janknecht, R., C. Sander, and O. Pongs. 1991. (HX)n repeats: A $\mathrm{pH}$-controlled protein-protein interaction motif of eukaryotic transcription factors? FEBS Lett. 295: 1-2.

Jiang, J., D. Kosman, Y.T. Ip, and M. Levine. 1991. The dorsal morphogen gradient regulates the mesoderm determinant twist in early Drosophila embryos. Genes \& Dev. 5: 18811891.

Knust, E., K.A. Bremer, H. Vässin, A. Ziemer, U. Tepass, and J.A. Campos-Ortega. 1987. The Enhancer of split locus and neurogenesis in Drosophila melanogaster. Dev. Biol. 122: 262-273.

Lees, A.D. and C.H. Waddington. 1942. The development of the bristles in normal and some mutant types of Drosophila melanogaster. Proc. Roy. Soc. Lond. B. Biol. Sci. 131: 87110.

Lindsley, D.L. and G. Zimm. 1992. The genome of Drosophila melanogaster. Academic Press, San Diego, CA.

Maniatis, T., E.F. Fritsch, and J. Sambrook. 1982. Molecular cloning: A laboratory manual. Cold Spring Harbor Laboratory, Cold Spring Harbor, New York.

Marck, C. 1988. "DNA strider": A " $\mathrm{C}$ " program for the fast analysis of DNA and protein sequences on the Apple Macintosh family of computers. Nucleic Acids Res. 16: 18291836.

Nash, D. 1965. The expression of Hairless in Drosophila and the role of two closely linked modifiers of opposite effect. Genet. Res. 6: 175-189.

- 1970. The mutational basis for the allelic modifier mutants, Enhancer and Suppressor of Hairless, of Drosophila melanogaster. Genetics 64: 471-479.

Nasmyth, K., D. Stillman, and D. Kipling. 1987. Both positive and negative regulators of $\mathrm{HO}$ transcription are required for mother-cell-specific mating-type switching in yeast. Cell 48: $579-587$.

Pirrotta, V. 1986. Cloning Drosophila genes. In Drosophila: $A$ practical approach (ed. D.B. Roberts), pp. 102. IRL Press, Oxford, England.

- 1988. Vectors for P-mediated transformation in Drosophila. In Vectors: A survey of molecular cloning vectors and their uses (ed. R.L. Rodriguez and D.T. Denhardt), pp. 437456. Butterworth, Stoneham, MA.

Robertson, H.M., G.R. Preston, R.W. Phillis, D.M. JohnsonSchlitz, W.K. Benz, and W.R. Engels. 1988. A stable source of P-element transposase in Drosophila melanogaster. Genetics 118: 461-470.

Rodriguez, I., R. Hernandez, J. Modolell, and G.M. Ruiz. 1990. Competence to develop sensory organs is temporally and spatially regulated in Drosophila epidermal primordia. EMBO I. 9: 3583-3592.

Rubin, G.M. and A.C. Spradling. 1982. Genetic transformation of Drosophila with transposable element vectors. Science 218: 348-353.

Shellenbarger, D.L. and J.D. Mohler. 1978. Temperature-sensitive periods and autonomy of pleiotropic effects of $1(1) N^{t s 1}$, a 
conditional Notch lethal in Drosophila. Dev. Biol. 62: 432446.

Simpson, P. 1990. Lateral inhibition and the development of the sensory bristles of the adult peripheral nervous system of Drosophila. Development 109: 509-519.

Skeath, J.B. and S.B. Carroll. 1991. Regulation of achaete-scute gene expression and sensory organ pattern formation in the Drosophila wing. Genes \& Dev. 5: 984-995.

Suter, B. and R. Steward. 1991. Requirement for phosphorylation and localization of the Bicaudal-D protein in Drosophila oocyte differentiation. Cell 67: 917-926.

Schweisguth, F. and J.W. Posakony. 1992. Suppressor of Hairless, the Drosophila homolog of the mouse recombination signal-binding protein gene, controls sensory organ cell fates. Cell 69: 1199-1212.

Tautz, D. and C. Pfeifle. 1989. A non-radioactive in situ hybridization method for the localization of specific RNAs in Drosophila embryos reveals translational control of the segmentation gene hunchback. Chromosoma 98: 81-85.

Vässin, H., J. Vielmetter, and J.A. Campos-Ortega. 1985. Genetic interactions in early neurogenesis of Drosophila melanogaster. J. Neurogen. 2: 291-308.

Wickens, M. 1990. In the beginning is the end: Regulation of poly(A) addition and removal during early development. Trends Biochem. Sci. 15: 320-324. 


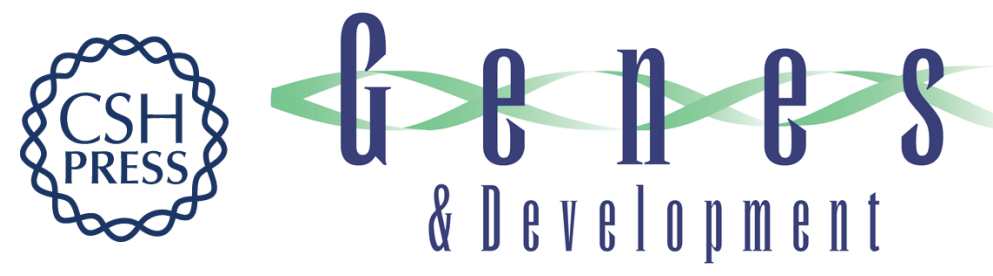

\section{The Drosophila gene Hairless encodes a novel basic protein that controls alternative cell fates in adult sensory organ development.}

A G Bang and J W Posakony

Genes Dev. 1992, 6:

Access the most recent version at doi:10.1101/gad.6.9.1752

References This article cites 36 articles, 15 of which can be accessed free at:

http://genesdev.cshlp.org/content/6/9/1752.full.html\#ref-list-1

License

Email Alerting

Service

Receive free email alerts when new articles cite this article - sign up in the box at the top right corner of the article or click here.

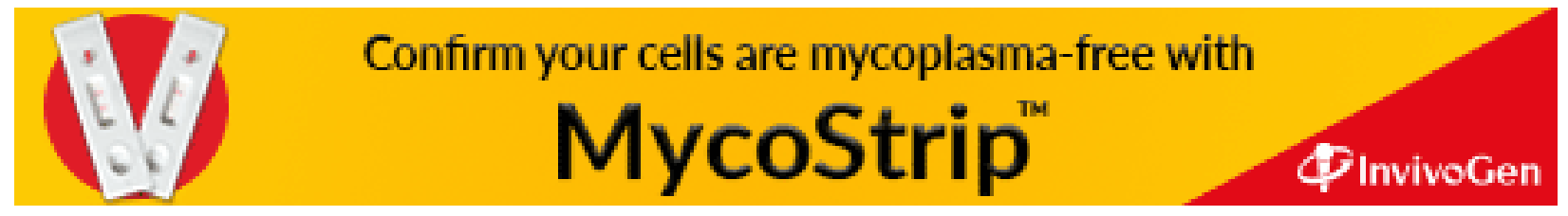

